\title{
Applying Pharmacokinetic/Pharmacodynamic Principles in Critically III Patients: Optimizing Efficacy and Reducing Resistance Development
}

\author{
Mohd H. Abdul-Aziz, BPharm Jeffrey Lipman, MD ${ }^{1,2}$ Johan W. Mouton, PhD ${ }^{3,4}$ William W. Hope, PhD
}

Jason A. Roberts, $\mathrm{PhD}^{1,2,5}$

${ }^{1}$ Burns, Trauma and Critical Care Research Centre, The University of Queensland, Brisbane, Queensland, Australia

2 Department of Intensive Care Medicine, Royal Brisbane and Women's Hospital, Brisbane, Queensland, Australia

${ }^{3}$ Department of Medical Microbiology, Radboud University, Nijmegen and Critical Care Research Centre, The University of Queensland, Leve 3, Ned Hanlon Building, Royal Brisbane and Women's Hospital, Herston, Queensland 4029, Australia (e-mail: j.roberts2@uq.edu.au).

Medical Centre, Nijmegen, The Netherlands

${ }^{4}$ Department of Medical Microbiology and Infectious Diseases,

Erasmus MC, Rotterdam, The Netherlands

${ }^{5}$ Department of Molecular and Clinical Pharmacology, University of Liverpool, Liverpool, United Kingdom,

Semin Respir Crit Care Med 2015;36:136-153.
Abstract
Keywords
- antibiotic
- resistance
- pharmacodynamics
- pharmacokinetics
- antibiotic dosing

The recent surge in multidrug-resistant pathogens combined with the diminishing antibiotic pipeline has created a growing need to optimize the use of our existing antibiotic armamentarium, particularly in the management of intensive care unit (ICU) patients. Optimal and timely pharmacokinetic/pharmacodynamic (PK/PD) target attainment has been associated with an increased likelihood of clinical and microbiological success in critically ill patients. Emerging data, mostly from in vitro and in vivo studies, suggest that optimization of antibiotic therapy should not only aim to maximize clinical outcomes but also to include the suppression of resistance. The development of antibiotic dosing regimens that adheres to the PK/PD principles may prolong the clinical lifespan of our existing antibiotics by minimizing the emergence of resistance. This article summarizes the relevance of PK/PD characteristics of different antibiotic classes on the development of antibiotic resistance. On the basis of the available data, we propose dosing recommendations that can be adopted in the clinical setting, to maximize therapeutic success and limit the emergence of resistance in the ICU.
Severe infections leading to severe sepsis and septic shock are prominent causes of morbidity and mortality in critically ill patients. In a large multicenter point prevalence study involving 1,265 intensive care units (ICUs) across 75 countries, $51 \%$ of ICU patients were classified as infected on the day of study with a mortality rate of $25.3 \%{ }^{1}$ Data from a large European ICU study has further corroborated the diagnosis of severe sepsis as a global healthcare crisis, whereby the condition accounted for $26.7 \%$ of ICU admissions. ${ }^{2}$ In this study, the corresponding mortality in patients with severe sepsis and septic shock was of concern, with rates of 32.2 and
$54.1 \%$, respectively. ${ }^{2}$ Despite an emerging trend for improved survival over recent years, ${ }^{3-5}$ the mortality rate in this patient cohort remains unacceptably high worldwide. ${ }^{6}$ In the context of the financial burden incurred, the United States is currently spending between $\$ 121$ and $\$ 263$ billion annually on critically ill patients, which represents more than $8 \%$ of the country's total healthcare expenditure. ${ }^{7}$

To address these persisting poor patient outcomes, significant amounts of research have been directed toward optimizing the provision of care for the critically ill patient. Indeed, improving antibiotic therapy is a core focus of
Issue Theme Antimicrobial Resistance: Management of Superbugs; Guest Editor, David L. Paterson, MBBS, PhD, FRACP, FRCPA
Copyright @ 2015 by Thieme Medical Publishers, Inc., 333 Seventh Avenue, New York, NY 10001, USA. Tel: +1(212) 584-4662.
DOI http://dx.doi.org/ 10.1055/s-0034-1398490. ISSN 1069-3424. 
treatment of infection-driven pathologies such as sepsis. There is strong evidence to suggest that optimal antibiotic therapy may have a greater impact on patients' survival when compared with novel treatment strategies such as the use of activated protein $\mathrm{C}^{8}$ antithrombin $\mathrm{III}^{9}$ and intensive insulin therapy in these patients. ${ }^{10-13}$ However, the process of optimizing antibiotic therapy can be a daunting challenge in the ICU for a variety of reasons. Extreme physiological derangements that can occur from either pharmacological interventions or the natural course of critical illness may alter antibiotic concentrations and consequently reduce antibiotic exposure in critically ill patients. ${ }^{14}$ In addition, pathogens that are usually isolated in the ICU differ from the general wards, as they are commonly less susceptible to common antibiotics. ${ }^{15,16}$ Indeed, antibiotic dosing that does not account for these features is likely to lead to suboptimal antibiotic exposure and therapeutic failures. In addition, suboptimal antibiotic exposure is also highly implicated as a contributing factor to the escalation of antibiotic resistance. Resistance to antibiotics certainly is considered a global healthcare crisis which currently threatens the advances of modern medicine. ${ }^{17}$

The recent surge in multidrug-resistant (MDR) pathogens combined with the diminishing antibiotic pipeline has created a growing need to optimize the use of the existing antibiotic armamentarium, particularly in the ICU. Although critically ill patients constitute fewer than $10 \%$ of all hospital admissions, their antibiotic consumption is 10 times greater compared with patients in all other wards. ${ }^{18-20}$ The rampant antibiotic use (or misuse) has therefore, in part, contributed to the alarming increase in the MDR pathogens such as the extended spectrum $\beta$-lactamases and carbapenemase-producing gram-negative pathogens. Notably, gram-negative pathogens such as Acinetobacter baumannii and Pseudomonas aeruginosa, as well as members of the Enterobacteriaceae family such as Escherichia coli and Klebsiella pneumoniae, which were previously considered relatively innocuous, have impressively out-maneuvered our current antibiotics. Previously simple infections have become increasingly difficult to treat over a short period of time. ${ }^{21}$ Moreover, infections caused by these pathogens frequently result in poor clinical outcomes, including higher mortality and prolonged hospitalisation. ${ }^{22-24}$ The healthcare community concerns are legitimate, as the emergence of resistance is likely to far outpace the rate of development of new antibiotics. In light of these grim prospects, clinicians are currently forced to reintroduce older antibiotics as treatment options (e.g., colistin and fosfomycin) and vigorously search for new strategies that can optimize the use of our presently available antibiotics.

The aim of this article is to describe the relevance of pharmacokinetic (PK) exposure and pharmacodynamic (PD) characteristics of different antibiotic classes on the development of antibiotic resistance. We will discuss the relevant antibiotic resistance descriptors and review how target drug exposures differ between predicting treatment success and suppressing resistance development. On the basis of these current data, we will also suggest dosing strategies that ultimately exploit antibiotic pharmacodynamics which in- crease the likelihood of treatment success as well as minimize the emergence of resistance.

\section{Applied Clinical Pharmacology of Antibiotics}

Pharmacology is the science of drugs including the study of drug actions. Two principle areas of pharmacology are PK and PD. Traditionally, antibiotic dosing and administration were only optimized, in accordance with the PK/PD principles, for clinical efficacy (i.e., clinical and microbiological cure) with an associated collateral damage being the selection of resistant pathogens. Emerging data are suggesting that the PD-based dosing approach should not only aim to maximize clinical outcomes but also to include the suppression of resistance. Indeed, the application of PK/PD principles has been shown to minimize the risk of emergence of resistance by avoiding ineffective antibiotic exposure, which consequently exerts a selective pressure to pathogens, rather than to eradicate them. ${ }^{25}$ This selective pressure causes the elimination of highly susceptible, but not the more resistant colonies, leading to future colonization and potential infection with poorly susceptible pathogens.

\section{Pharmacokinetic Considerations}

PK refers to the study of concentration changes of a drug over a given time period. This branch of pharmacology describes the rates and processes from absorption to distribution of drugs to elimination mechanism via metabolism or excretion. Some of the examples of important PK parameters are (1) volume of distribution $\left(\mathrm{V}_{\mathrm{d}}\right)$, (2) clearance $(\mathrm{CL}),(3)$ maximum drug concentration over a dosing interval $\left(\mathrm{C}_{\max }\right)$, (4) minimum drug concentration during a dosing interval $\left(\mathrm{C}_{\min }\right)$, and (5) area under the concentration-time curve from 0 to 24 hours $\left(\mathrm{AUC}_{0-24}\right)$. Among these however, alterations in the primary $P K$ parameters, namely $\mathrm{V}_{\mathrm{d}}$ and $\mathrm{CL}$, are probably the most influential in determining altered antibiotic dosing and exposure. Changes in antibiotic $V_{d}$ and $C L$ have been commonly observed in critically ill patients and the relevance of the two phenomena in influencing effective antibiotic exposure has been reviewed in detail elsewhere. ${ }^{26}$

\section{Pharmacodynamic Considerations}

PD describes the relationship between PK exposure and pharmacological effect. For antibiotics, PD relates the antibiotic concentration to the ability of an antibiotic to kill or inhibit the growth of a pathogen. In general, this relationship is often described by linking the concentration of an antibiotic with the corresponding minimum inhibitory concentration (MIC) of the offending pathogen. For an antibiotic, it is the free or unbound concentration that is responsible for the antibiotic activity. ${ }^{27}$ Numerous studies have demonstrated that different antibiotics have different PD properties and can be readily categorized as the following: (1) the duration of time that free drug concentration remains above the MIC during a dosing interval ( $\left.f \mathrm{~T}_{>\mathrm{MIC}}\right)$, (2) the ratio of $\mathrm{C}_{\max }$ to MIC, and (3) the ratio of $\mathrm{AUC}_{0-24}$ to MIC. These fundamental PK/PD indices for antibiotics' activity are further illustrated in - Fig. 1. It should be noted that the AUC/MIC was never 


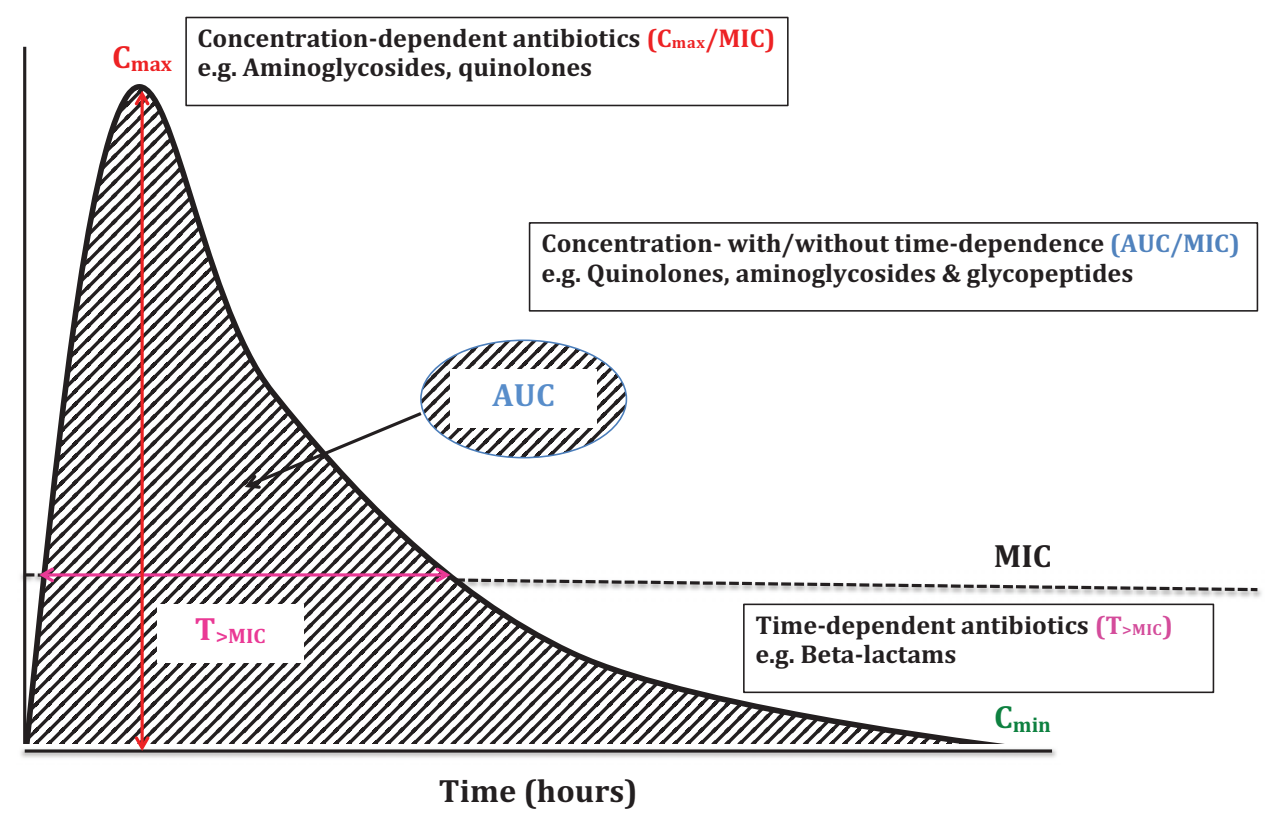

Fig. 1 The graphical illustration of fundamental pharmacokinetic and pharmacodynamic parameters of antibiotics on a hypothetical concentration-time curve. AUC, area under the concentration-time curve; $C_{\max }$, maximum drug concentration; $C_{\min }$, minimum drug concentration; MIC, minimum inhibitory concentration; $T_{>M I C}$, duration of time that drug concentration remains above MIC.

considered in earlier studies, and that many data retrieved from older literature established only the relationship between $\mathrm{C}_{\text {max }} / \mathrm{MIC}$ and effect parameter. From a theoretical point of view, most of the antibiotics should show a relationship with AUC and effect rather than $C_{\max }$.

Based on the PK/PD indices, antibiotics can be classified into three categories that, by and large reflect their modes of bacterial killing. ${ }^{28-30}$ The first category includes antibiotics where the difference between the maximum effect and minimum effect is relatively large, and increasing concentrations result in progressively increased killing. Therefore, these are also sometimes called concentration-dependent antibiotics, and include aminoglycosides and quinolones. For these antimicrobials, AUC/MIC describes their antibiotic activity best, and, mainly because AUC/MIC is closely correlated to $\mathrm{C}_{\max } / \mathrm{MIC}, \mathrm{C}_{\max } / \mathrm{MIC}$ as well. ${ }^{31,32}$ On the other hand, time-dependent antibiotics' activity, such as the $\beta$-lactams, is strongly correlated with $f \mathrm{~T}_{>\text {MIC }}$ and as such, prolonging the duration of effective drug exposure should be the priority when this antibiotic class is used. ${ }^{33,34}$ However, some antibiotics such as the glycopeptides are more complex where they are found to display both concentration- and timedependent kill characteristics. ${ }^{34}$ For these antibiotics, the ratio of $\mathrm{AUC}_{0-24} / \mathrm{MIC}$ describes their antibiotic activity best and higher thresholds are closely related to successful clinical outcome. $^{35}$

\section{Pharmacokinetic|Pharmacodynamic Considerations and the Resistance Descriptors}

Most of the earlier research on optimizing antibiotic dosing was focused only on maximizing clinical and microbiological cure and not on minimization of the emergence of antibiotic resistance. To date, most of the data describing PK/PD and its association with antibiotic resistance comes from preclinical, albeit advanced, PK/PD infection models. However, the antibiotic exposure required for clinical efficacy and resistance suppression is markedly different. For instance, the antibiotic exposure-response relationship for clinical efficacy is monotonic or can also be described as a sigmoidal relationship in which no measurable antibiotic effect is expected at lower drug exposures while larger exposures are expected to augment the bactericidal effect up to a certain threshold. In contrast, the relationship between antibiotic exposure and the selection of resistant mutants is markedly non-monotonic and has the shape of an inverted "u," where resistant mutants are amplified with initial antibiotic exposure and then slowly decline with increasing exposure up to an optimal threshold that ultimately prevents resistance amplifications. ${ }^{36-39}$ The inverted $\mathrm{U}$-shape seems to follow a log normal distribution. ${ }^{40}$ In addition, Jumbe et $\mathrm{al}^{40}$ found that an $\mathrm{AUC}_{0-24} / \mathrm{MIC}$ of $\geq 110$ for levofloxacin, which was twice that was necessary for optimal bactericidal effect, was required to suppress drugresistant population of $P$. aeruginosa in a mouse thigh infection model. ${ }^{41}$ This information, among other similar observations, has indicated that the magnitude of the PK/PD indices for resistance suppression is generally different and higher than the thresholds required for clinical success. ${ }^{37,42-44}$ Therefore, antibiotic dosing that only aims to optimize clinical efficacy may potentially amplify resistance formation by selecting mutant bacterial strains with reduced drug susceptibility. With enhanced knowledge on antibiotic PK/PD over recent years, important hypotheses and concepts, such as the mutant selection window (MSW) and mutant prevention concentrations (MPCs), have been proposed to provide 
potential explanations as to how suboptimal antibiotic exposure may amplify the selection of resistant bacterial strains. In addition, the dynamics of bacterial populations under various dosing regimens can be described using mixture models, where changes in susceptible and resistant subpopulations in relation to drug concentrations are quantified. ${ }^{38,41,42,45,46}$

\section{Mutant Selection Window}

The term "selective window" (SW), which was first coined by Baquero, ${ }^{4,48}$ refers to a critical range of antibiotic concentrations in which drug-resistant bacterial mutants could be selectively enriched and amplified when exposed to concentrations in this zone. Subsequent in vitro studies, utilizing mycobacteria treated with quinolones, were able to define the boundaries for the critical zone of antibiotic concentrations and this concept was later renamed as the MSW. ${ }^{49-51}$ Studies that attempted to describe MSW further suggested that these concentration zones are those between the MIC of the susceptible pathogens and that of the least susceptible mutants. - Fig. 2 illustrates the concept of MSW and its relevance in the development of resistant mutants. In addition to this, the formation of the resistant mutants was observed to be most intense in the bottom portion as opposed to the upper portion of the selection window. ${ }^{52}$ The existence of such "dangerous" concentration zones was further corroborated by several in vitro ${ }^{39,53-55}$ and in vivo experimental studies. $^{56-59}$
The MSW hypothesis is potentially important, as contemporary antibiotic dosing tends to produce drug concentrations within the critical zone where they selectively amplify the growth of resistant mutants. Essentially, the higher the percentage of time $(t)$ spent by an antibiotic within the MSW ( $t$ MSW), the greater the opportunity for resistant mutants to be selected and amplified. Furthermore, the continuous and prolonged "careless" practice of "dosing to only cure" in the ICU eventually leads to the resistant mutants being the dominant bacterial population and it is only at this point that surveillance studies would be alerted to the emergent resistant isolates. The MSW has been defined for many of the quinolones and some of the $\beta$-lactams against various microorganisms. ${ }^{60-62}$ Nevertheless, this concept is currently considered as a relatively new idea and has not been investigated in many infective pathologies, nor its relevance at the site of infection. Hence, its clinical relevance in optimizing antibiotic dosing to avoid the MSW remains unclear and warrants further investigation.

\section{Mutant Prevention Concentration}

The concept of MPC, which was derived from the MSW hypothesis, refers to the antibiotic concentration that corresponds to the MIC of the least susceptible mutants in a colony. $^{49,51}$ While MIC refers to the lower boundary, the MPC essentially represents the upper boundary of concentrations in the MSW in which the enrichment of resistant

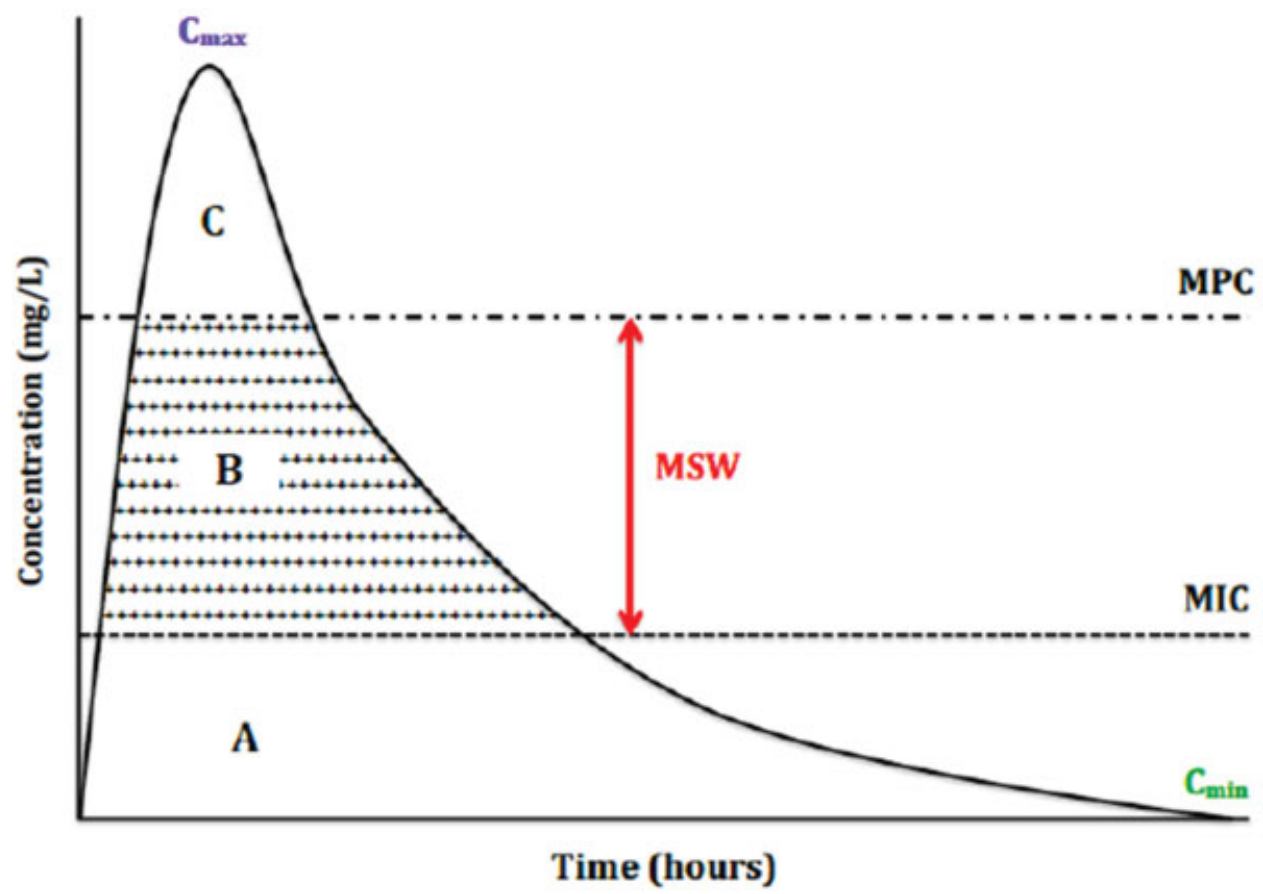

Fig. 2 Graphical illustration of the mutant selection window and mutant prevention concentration on a hypothetical concentration-time curve. The MSW describes the range of antibiotic concentrations where resistant mutants may be selectively amplified and these concentration zones are those between the MIC of the susceptible pathogens and that of the least susceptible mutants, i.e., MPC. In area (A), which is below the MIC, no resistant mutants are expected to grow, as there is no selective pressure in this area. In area (C), which is above the MPC, the growth of resistant mutants is severely restricted and highly unlikely as the exposure in the area is able to suppress the growth of the least susceptible pathogens. On the contrary, the selection of resistant mutants would be most intense in area (B) which is also known as MSW. Conversely, the longer the time spent by an antibiotic in this concentration zone, the greater the opportunity for resistant mutants to be selected and amplified. $C_{\max }$, maximum drug concentration; $C_{\min }$, minimum drug concentration; MIC, minimum inhibitory concentration; MPC, mutant prevention concentration; MSW, mutant selection window. 
mutants are expected to be severely hindered. Conversely, antibiotic dosing that aims to achieve concentrations higher than the MPC, as opposed to MIC, theoretically provides both an optimal bactericidal effect and resistance suppression. Furthermore, the ratio of $\mathrm{AUC}_{0-24}$ to $\mathrm{MPC}\left(\mathrm{AUC}_{0-24} / \mathrm{MPC}\right)$ as opposed to $\mathrm{AUC}_{0-24} / \mathrm{MIC}$ is also suggested as a predictor of the development of resistance in several in vitro and in vivo evaluations as MIC quantifications generally ignore mutant subpopulations. ${ }^{36,60,63,64}$ The argument has been mostly tested in in vitro studies for quinolones where the mutantrestrictive thresholds of $\mathrm{AUC}_{0-24} / \mathrm{MPC}$ were approximately one-third of those $\mathrm{AUC}_{0-24} / \mathrm{MIC}$ values. ${ }^{39,65}$

The MPC has been described mostly for quinolones, although data for other classes of antibiotics are emerging. ${ }^{60,66,67}$ Quantifying MPC thresholds for individual antibiotics should be one of the priorities in the development of dosing guidelines especially earlier in the process of evaluation and screening of new compounds. Although the concept seems appealing, the application, however, is not straightforward, as the doses needed to achieve the MPC are usually higher than those for curing patients and exceed those that are registered for those antibiotics. There are also examples where these concentrations are unattainable for some antibiotic-pathogen combination. ${ }^{50,67}$ In addition, a trade-off between an increased risk of adverse effects with minimizing antibiotic resistance is a difficult consideration in clinical practice. In such cases, combining two or three antibiotics with overlapping PD properties may be warranted.

\section{Application of Experimental Mixture Models}

Mixture models examine resistance development by describing the population dynamics of antibiotic-susceptible and -resistant bacteria during the course of treatment. Susceptible and resistant subpopulations respond differently to different antibiotic concentrations.

In a murine thigh infection model, Jumbe et al investigated the impact of bacterial inoculum on the required levofloxacin exposure for the eradication of the total $P$. aeruginosa population. ${ }^{41}$ The mice were inoculated with either $10^{7}$ or $10^{8}$ bacteria per thigh and levofloxacin was initiated after 2 hours. The investigators demonstrated that the exposure intensity which is required for maximal levofloxacin activity increases (by two- to fivefold) as the size of the inoculum increases by 1 log. This phenomenon occurs as a larger bacterial challenge constitutes larger population of resistant mutants, which are less susceptible to antibiotic therapy. The investigators also employed a complex mathematical model to analyze their findings and simultaneously calculate an exposure that would amplify resistant population and restrict the enrichment of the population. A free AUC/MIC ratio of 110 and 36 was predicted to prevent and amplify resistant $P$. aeruginosa mutants in the study, respectively.

\section{Specific Antibiotic Classes}

This section discusses individual antibiotic classes and their pharmacodynamic characteristics, which influence antibiotic activity and the prevention of resistance. The relevant PD indices that have been shown to correlate with both outcomes are presented in -Table $\mathbf{1}$.

\section{Quinolones}

Quinolones are mostly lipophilic antibiotics and display largely concentration-dependent kill characteristics but with some time-dependent effects. Previous in vitro studies have shown that the achievement of a $\mathrm{C}_{\max } / \mathrm{MIC}$ ratio of at least 8 to 12 is important for optimal bactericidal activity. ${ }^{68,69}$ Given the halflife of most quinolones, this corresponds to $\mathrm{AUC}_{0-24} / \mathrm{MIC}$ values that correlate to efficacy. More important, however, is that the index has also been associated with the reduction of resistant mutants in several experimental studies. ${ }^{70-72}$

Several studies found that the ratio of $\mathrm{AUC}_{0-24} / \mathrm{MIC}$ is important for its bactericidal effect, as an even more significant index as compared with the $\mathrm{C}_{\mathrm{max}} / \mathrm{MIC}$ ratio, and a ratio of $\geq 125$ and $\geq 30$ has been advocated for clinical success in the treatment of gram-negative and -positive infections, respectively. ${ }^{71,73-77}$ In the context of antibiotic resistance, an inverse relationship has been described between this index and the probability of developing resistance. ${ }^{78}$ Accordingly, quinolone dosing regimens that ensure higher ratios of $\mathrm{AUC}_{0-24}$ MIC are currently recommended to maximize bactericidal exposure as well as minimizing the development of resistance. ${ }^{38,41,78}$ Several investigators have further elucidated the critical $\mathrm{AUC}_{0-24} / \mathrm{MIC}$ thresholds as being between $>100$ and 200 to suppress the formation of resistant mutants when these antibiotics are used for gram-negative infections. ${ }^{41,78,79}$ However, owing to intrinsic differences between various quinolones in selecting resistant strains, the suggested $\mathrm{AUC}_{0-24} / \mathrm{MIC}$ ratio for resistance suppression may vary between individual agents. ${ }^{71,80}$

The $\mathrm{AUC}_{0-24} / \mathrm{MPC}$ index is also being investigated and the advantages over $\mathrm{AUC}_{0-24} / \mathrm{MIC}$ in the prediction of resistance development have been documented in several in vitro studies. ${ }^{60,63,64}$ To date, this remains a controversial argument as most authors found that both indices were similar in their predictive potentials of resistance development. ${ }^{57,81}$ Nevertheless, higher ratios of $\mathrm{AUC}_{0-24} / \mathrm{MPC}$ are associated with minimizing the emergence of resistance.

Recently, increasing interest and efforts have been focused on the application of MSW concept in the evaluation of quinolones dosing regimens. Based on the current data, $t$ MSW of $\leq 30 \%$ should restrict mutant amplification and the index has been studied in several in vitro ${ }^{55,82}$ and in vivo studies. ${ }^{57,61}$ Khachman et al further extended this concept into clinical practice by investigating the appropriateness of the currently recommended ciprofloxacin dosing in 102 critically ill patients. ${ }^{83}$ Using Monte Carlo simulations, the probability of target attainment (i.e., $\leq 20 \% t \mathrm{MSW}$ ) for the currently recommended ciprofloxacin dosing regimens (i.e., $800 \mathrm{mg}$ or $1,200 \mathrm{mg} /$ daily) was less than $50 \%$ and when higher doses such as $2,400 \mathrm{mg} /$ daily were used, only minor improvements were observed, that is, probability of target attainment of $61 \%$. More importantly, the risk of selecting resistant $A$. baumannii and $P$. aeruginosa strains were extremely high with the recommended regimens, thus challenging their appropriateness in critically ill patients. As it 
Table 1 Optimal pharmacokinetic/pharmacodynamic indices for antibiotic activity and the magnitudes associated with maximal therapeutic outcomes and resistance suppression ${ }^{\mathrm{a}}$

\begin{tabular}{|c|c|c|c|c|c|}
\hline Antibiotic class & $\begin{array}{l}\text { Optimal PK/PD } \\
\text { index }\end{array}$ & $\begin{array}{l}\text { PK/PD magnitude } \\
\text { for bacterial } \\
\text { killing }\end{array}$ & $\begin{array}{l}\text { PK/PD magnitude } \\
\text { for clinical efficacy }\end{array}$ & $\begin{array}{l}\text { Optimal PK/PD } \\
\text { index for } \\
\text { resistance } \\
\text { suppression }\end{array}$ & $\begin{array}{l}\text { PK/PD magnitude } \\
\text { for resistance } \\
\text { suppression }^{\mathrm{d}}\end{array}$ \\
\hline \multirow[t]{2}{*}{ Aminoglycosides } & $\mathrm{AUC}_{0-24} / \mathrm{MIC}$ & $\begin{array}{l}\text { AUC }_{0-24 / M I C:} /{ }^{8}- \\
160^{86,88,90}\end{array}$ & $\begin{array}{l}\text { AUC }_{0-24 / \mathrm{MIC}: 50-} \\
100^{89}\end{array}$ & $\mathrm{C}_{\max } / \mathrm{MIC}$ & $C_{\max } / M I C \geq 20^{94}$ \\
\hline & $\mathrm{C}_{\max } / \mathrm{MIC}$ & - & $\mathrm{C}_{\max } / \mathrm{MIC} \geq 8^{31,66,87}$ & & $C_{\max } / M I C \geq 30^{94}$ \\
\hline Penicillins & $\mathrm{T}_{>\mathrm{MIC}}$ & $\geq 40-50 \% \mathrm{~T}_{>\mathrm{MIC}}{ }^{34}$ & $\geq 40-50 \% \mathrm{~T}_{>\mathrm{MIC}}$ & $T_{>M I C}$ & $\geq 40-50 \% \mathrm{~T}_{>\mathrm{MIC}}{ }^{62}$ \\
\hline Cephalosporins & $\mathrm{T}_{>\mathrm{MIC}}$ & $\geq 60-70 \% \mathrm{~T}_{>\mathrm{MIC}}{ }^{34}$ & $\begin{array}{l}\geq 45-100 \% \\
\mathrm{~T}_{>\mathrm{MIC}} 32,99,102,103\end{array}$ & tMSW & $\leq 40 \%$ tMSW ${ }^{112}$ \\
\hline \multirow[t]{2}{*}{ Carbapenems } & $\mathrm{T}_{>\mathrm{MIC}}$ & $\geq 40 \% \mathrm{~T}_{>\mathrm{MIC}}{ }^{34}$ & $\begin{array}{l}\geq 50-75 \% \\
\mathrm{~T}_{>\mathrm{MIC}} 105,107\end{array}$ & $\mathrm{~T}_{>\mathrm{MIC}}$ & $\geq 40 \% \mathrm{~T}_{>\mathrm{MIC}}{ }^{116}$ \\
\hline & & & & tMSW & $\leq 45 \% t^{M S W^{117}}$ \\
\hline \multirow[t]{4}{*}{ Quinolones } & $\mathrm{AUC}_{0-24} / \mathrm{MIC}$ & $\begin{array}{l}\text { AUC }_{0-2,4 / \mathrm{MIC}: 30-} \\
200^{29,66,77}\end{array}$ & 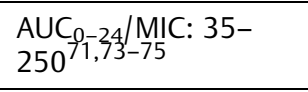 & $\mathrm{AUC}_{0-24} / \mathrm{MIC}$ & $\begin{array}{l}\mathrm{AUC}_{0-24} / \mathrm{MIC}: 100- \\
200^{38,4}\end{array}$ \\
\hline & $\mathrm{C}_{\max } / \mathrm{MIC}$ & $\begin{array}{l}\mathrm{C}_{\max } / \mathrm{MIC} \\
\geq 8^{68,69,72}\end{array}$ & $C_{\max } / \mathrm{MIC} \geq 8^{88}$ & $\mathrm{C}_{\max } / \mathrm{MIC}$ & $\mathrm{C}_{\max } / \mathrm{MIC} \geq 4^{70}$ \\
\hline & & & & $\mathrm{AUC}_{0-24} / \mathrm{MPC}$ & $\begin{array}{l}\mathrm{AUC}_{0-24 / \mathrm{MPC}} \\
\geq 22^{60}\end{array}$ \\
\hline & & & & tMSW & $\begin{array}{l}\leq 30 \% \\
\text { tMSW } 53,55,59,82\end{array}$ \\
\hline Vancomycin & $\mathrm{AUC}_{0-24} / \mathrm{MIC}$ & 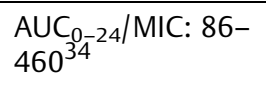 & $\begin{array}{l}\mathrm{AUC}_{0-24 / \mathrm{MIC}: 400-} \\
600^{34,128}\end{array}$ & $\mathrm{AUC}_{0-24} / \mathrm{MIC}$ & $\begin{array}{l}\text { AUC }_{0-24} / \mathrm{MIC}: \\
200^{53}\end{array}$ \\
\hline \multirow[t]{2}{*}{ Linezolid } & $\mathrm{AUC}_{0-24} / \mathrm{MIC}$ & $\begin{array}{l}\mathrm{AUC}_{0-24} / \mathrm{MIC}: 50- \\
80^{136}\end{array}$ & $\begin{array}{l}\mathrm{AUC}_{0-24 /} \\
\mathrm{MIC} \geq 80^{137}\end{array}$ & & \\
\hline & $\mathrm{T}_{>\mathrm{MIC}}$ & $\geq 40 \% \mathrm{~T}_{>\mathrm{MIC}}{ }^{136,138}$ & $\geq 85 \% \mathrm{~T}_{>\mathrm{MIC}}{ }^{137}$ & & \\
\hline \multirow[t]{2}{*}{ Daptomycin $^{\mathrm{e}}$} & $\mathrm{AUC}_{0-24} / \mathrm{MIC}$ & $\begin{array}{l}\text { AUC }_{0-24 / \mathrm{MIC}} \\
388-537^{149}\end{array}$ & - & $\mathrm{AUC}_{0-24} / \mathrm{MIC}$ & $\begin{array}{l}\text { AUC }_{0-24} / \mathrm{MIC}: \\
200^{53}\end{array}$ \\
\hline & $\mathrm{C}_{\max } / \mathrm{MIC}$ & $\begin{array}{l}C_{\max } / M I C: 59- \\
94^{149}\end{array}$ & - & & \\
\hline Fosfomycin & Unknown & - & - & - & - \\
\hline Colistin & $\mathrm{AUC}_{0-24} / \mathrm{MIC}$ & $\begin{array}{l}\text { AUC }_{0-24 / \mathrm{MIC}: 50-} \\
65^{175,176}\end{array}$ & - & - & - \\
\hline
\end{tabular}

Abbreviations: $\mathrm{AUC}_{0-24} / \mathrm{MIC}$, ratio of area under the concentration-time curve during a 24-hour period to minimum inhibitory concentration; $\mathrm{AUC}_{0-24} / \mathrm{MPC}$, ratio of area under the concentration-time curve during a 24-hour period to the concentration that prevents mutation; $C_{\text {max }} / \mathrm{MIC}$, ratio of maximum drug concentration to minimum inhibitory concentration; $T_{>\mathrm{MIC}}$, duration of time that drug concentration remains above the minimum inhibitory concentration during a dosing interval; tMSW, percentage of time spent by an antibiotic within the mutant selection window.

${ }^{a}$ All values refer to the nonprotein bound, free fraction except when indicated otherwise.

${ }^{b}$ Data have been summarized from in vivo animal studies and may utilize different infection models employing different bacteria. Where the index is reported as a range, specific data for the contributing indices, which may have been derived from different studies, can be found in the associated references. The data also reflect the 2 -log kill and in some cases 1 -log kill which may or may not coincide with maximum kill.

'Data have been summarized from clinical studies and may recruit different patient population. Where the index is reported as a range, specific data for the contributing indices, which may represent PK/PD thresholds for clinical or microbiological cure, can be found in the associated references. ${ }^{\mathrm{d}}$ Data have been summarized from preclinical studies, which may include in vitro and in vivo experimental infection models employing different bacteria. Specific data for the contributing indices can be found in the associated references.

eValues reported here refer to total drug concentration.

stands, a quinolone dosing regimen that maximizes the $\mathrm{AUC}_{0-24} / \mathrm{MIC}$ ratio should be considered in critically ill patients and by citing ciprofloxacin as an example; the objective may be achieved with a $400 \mathrm{mg} 8$-hour or $600 \mathrm{mg}$ 12-hour regimen. When treating pathogens with high MICs, dose escalation should be considered while being observant of possible occurrence of dose-related adverse effects.

\section{Aminoglycosides}

Aminoglycosides are hydrophilic in nature and they demonstrate concentration-dependent kill characteristics. ${ }^{31,84} \mathrm{Al}-$ though previous studies have mainly suggested that achieving a high $\mathrm{C}_{\max } / \mathrm{MIC}$ ratio predicts optimal outcome, ${ }^{32,85-88}$ Craig argued that the ratio of $\mathrm{AUC}_{0-24} / \mathrm{MIC}$ would be more appropriate in describing the antibiotic's 
activity. ${ }^{34}$ In the 1980 s, Moore et $\mathrm{al}^{32}$ suggested that an aminoglycoside dose that provided a $\mathrm{C}_{\max } / \mathrm{MIC}$ ratio of 8 to 10 was associated with a higher probability of clinical success against gram-negative infections. However, the investigators chose the index due to their sparse PK sampling times and consequently, $\mathrm{AUC}_{0-24} / \mathrm{MIC}$ ratio was not considered in the study. Importantly, high collinearity existed between $\mathrm{C}_{\max }$ and AUC. Several investigators have since suggested that the ratio of $\mathrm{AUC}_{0-24} / \mathrm{MIC}$ is more likely to be a "better" $\mathrm{PD}$ descriptor for aminoglycosides activity, ${ }^{29,89}$ in which an $\mathrm{AUC}_{0-24} / \mathrm{MIC}$ ratio of 80 to 160 has been advocated for its efficacy. ${ }^{89,90}$

Although higher concentrations enhance aminoglycoside activity, prolonged exposure of such concentrations may lead to drug toxicity as well as the development of bacterial resistance. This type of resistance is known as adaptive resistance and is characterized by a slow, but reversible, concentration-independent killing. ${ }^{91-93}$ Maximizing the $\mathrm{C}_{\max } / \mathrm{MIC}$ ratio seems to reduce the development of adaptive resistance and the objective is likely achieved with extended daily dosing (EDD) as opposed to the traditional dosing schemes (i.e., twice or thrice daily dosing) ${ }^{93}$ In a PD model designed to predict aminoglycosides activity against $A$. baumannii and $P$. aeruginosa, Tam et al further quantified the required $C_{\max } / \mathrm{MIC}$ ratio to prevent the resistance development. ${ }^{94}$ In this study, a $\mathrm{C}_{\max } / \mathrm{MIC}$ ratio of 20 for a once-daily amikacin dosing regimen and 30 for a 12-hour gentamicin dosing regimen was required for suppressing $A$. baumannii and $P$. aeruginosa regrowth, respectively. Based on these results, it could be inferred that the $\mathrm{C}_{\max } / \mathrm{MIC}$ and $\mathrm{AUC}_{0-24} /$ MIC ratios are the PD indices to consider for suppressing $A$. baumannii and $P$. aeruginosa resistant mutants, respectively.

Based on the available data, EDD rather than the traditional multiple daily dosing of aminoglycosides is currently advocated in an attempt to maximize their therapeutic potential and minimize resistance development. Furthermore, it has been shown in numerous clinical studies ${ }^{95,96}$ and several meta-analyses ${ }^{97,98}$ that the dosing recommendation is indeed appropriate and valid in reducing aminoglycosides toxicity and may increase the likelihood of successful treatment outcomes. Clinical data on these dosing effects on development of resistance remain sparse.

\section{Beta-Lactams}

The $\beta$-lactam antibiotics are made up of penicillins, cephalosporins, monobactams, and carbapenems. Because of their different spectrum and PD properties, carbapenems will be discussed separately in the following section. Beta-lactam antibiotics are generally hydrophilic in nature and display time-dependent kill characteristics. The percentage of $f \mathrm{~T}_{>\mathrm{MIC}}$ $\left(\% f \mathrm{~T}_{>\mathrm{MIC}}\right)$ is regarded as the optimal PD index for their activity and, as such, maintaining effective drug exposure above the MIC should be the priority when this antibiotic class is used. ${ }^{30}$ It has been generally suggested that the $\% f \mathrm{~T}_{>\text {MIC }}$ required for bactericidal effect is 50,60 to 70 , and $40 \%$ for penicillins, cephalosporins, and carbapenems, respectively. ${ }^{99-101}$ In addition, relatively higher $f \mathrm{~T}_{>\text {MIC }}$ exposures are needed for maximal activity against the gram negatives as opposed to the gram-positive pathogens. However, clinical data from critically ill patients have not consistently supported these targets. Some studies recommend these in vitro exposures to be the minimum antibiotic exposures required, with patients potentially benefiting from higher and longer antibiotic exposures than those previously described in in vitro and in vivo studies. ${ }^{33,102-106}$ It has also been demonstrated that maximal bactericidal activity occurs when drug concentrations are maintained at four to five times the MIC, with higher concentrations providing little added benefit. ${ }^{106-108}$ Therefore, it has been suggested that $\beta$-lactam concentrations should be maintained at least four to five times the MIC for extended periods during each dosing interval to ensure clinical success, particularly in severely ill patients. ${ }^{109}$

It is still inconclusive whether the $f \mathrm{~T}_{>\text {MIC }}$ index predicts $\beta$-lactam resistance, although the potential link has been described in several in vitro ${ }^{44}$ and in vivo experimental studies. ${ }^{62,110}$ Fantin et al utilized an in vivo animal model to suggest that the development of resistance against ceftazidime might arise should the drug concentration fall below the MIC for more than half of the dosing interval. ${ }^{110}$ The risk of developing resistance against a cephalosporin has also been linked to a low $\mathrm{AUC}_{0-24} / \mathrm{MIC}$ ratio. ${ }^{111}$ This was further demonstrated by Stearne et al who found that an $\mathrm{AUC}_{0-24}$ MIC of 1,000 was required with ceftizoxime to prevent the emergence of resistant Enterobacter cloacae strains. ${ }^{40}$ In another murine lung infection model, Goessens et al found that the growth of resistant $E$. cloacae strains was correlated with prolonged ceftazidime's $t$ MSW. ${ }^{112}$

Based on the limited data on resistance suppression, $\beta$-lactams dosing that targets concentrations greater than four times the MIC for extended periods would be most appropriate. ${ }^{113}$ Importantly, research has shown that the objective can be obtained via frequent dosing or by utilizing extended infusion (EI) or continuous infusion (CI). However, the altered dosing schemes may potentially drive the emergence of resistance with suboptimal dosing, at least in theory, as these approaches tend to increase $\beta$-lactams tMSW. In a recent in vitro hollow-fiber infection model (HFIM) of $P$. aeruginosa, Felton et al suggested that EI of piperacillin/ tazobactam was equivalent to intermittent bolus (IB) dosing in terms of the bactericidal effect and the prevention of resistance. ${ }^{14}$ However, the target concentration for the two approaches should be different in which the ratio of $\mathrm{C}_{\min } / \mathrm{MIC}$ of 10.4 and 3.4 was required by EI and IB to suppress resistant mutants, respectively.

\section{Carbapenems}

In general, carbapenems have similar PK/PD characteristics when compared with other $\beta$-lactam antibiotics. Some studies have suggested that unlike other $\beta$-lactams, carbapenems possess a postantibiotic effect (PAE) against gram-negative bacilli, including $P$. aeruginosa strains, ${ }^{114}$ although this could not be confirmed in another study. ${ }^{115}$ This PAE property of carbapenems may explain a shorter $\% f \mathrm{~T}_{>\text {MIC }}$ for optimal bactericidal activity. Li et al further quantified the $\% f T_{>M I C}$ as $>54 \%$ to achieve optimal microbiological outcome when meropenem is used in patients with lower respiratory tract 
infections. ${ }^{107}$ In addition, only a ratio of $\mathrm{C}_{\text {min }} / \mathrm{MIC}$ of $>5$ was significantly associated with clinical and microbiological cure in this cohort of patients. Further, Tam et al used an in vitro HFIM to demonstrate that a $\mathrm{C}_{\min } / \mathrm{MIC}$ of $>6.2$ was required to suppress the development of resistant $P$. aeruginosa mutants. ${ }^{108}$ The finding was later corroborated by the same group of investigators in a neutropenic mouse infection model, and in this current analysis, $\% f \mathrm{~T}_{>\text {MIC }}$ of $>40 \%$ was also associated with the selection of resistant mutants. ${ }^{116}$ Recently in an in vitro dynamic model simulating doripenem concentrations, Zinner et al found that resistant $P$. aeruginosa mutants were likely to be selected at drug concentrations that fell $\geq 45 \%$ within the MSW ( $\geq 45 \% t$ MSW). ${ }^{117}$

Similar to the other $\beta$-lactam antibiotics, maintaining carbapenem concentrations at four to six times the MIC for extended periods is currently advocated to suppress the selection of resistant mutants. To achieve this objective, prolonging the duration of infusion is generally recommended when the antibiotic is used. However, EI instead of $\mathrm{CI}$ is the currently preferred dosing method when carbapenems are used considering the group's inherent drug instability in aqueous solutions. With increasing information and emerging data, clear distinction, in the context of stability problems, needs to be emphasized between the different members of the carbapenem group. While imipenem is indeed less stable, there are currently no practical reasons to oppose continuous meropenem infusion, as it has been successfully administered up to 8 hours (in a hospital environment) in numerous clinical studies without drug instability or degradation reports. ${ }^{118-120}$ In an in vitro HFIM examining cell-kill and resistance suppression for three $P$. aeruginosa strains, Louie et al demonstrated that a doripenem dosing regimen of $1 \mathrm{~g}$ infused over 4 hours was the solitary regimen that was able to completely suppress resistance for the full period of 10 days for wild-type isolates. ${ }^{121}$ Importantly, the investigators also reported that the dosing regimen produces concentrations at $>6.2$ times the MIC which were significantly associated with maximal resistance suppression in other evaluations. ${ }^{44,117}$ In addition, Chastre et al also observed lower occurrence of resistant $P$. aeruginosa strains arising in patients treated with EI of doripenem when compared with patients who received conventional imipenem dosing in a multicenter, randomized controlled trial of critically ill patients with ventilator-associated pneumonia. ${ }^{122}$

\section{Vancomycin}

Vancomycin is a glycopeptide antibiotic and is a relatively hydrophilic drug. Some in vitro ${ }^{123,124}$ and in vivo animal studies ${ }^{125}$ suggest that the bactericidal activity of the antibiotic is time dependent, whereas some have shown the ratio of $\mathrm{C}_{\text {max }} / \mathrm{MIC}$ to be equally important. ${ }^{126}$ Recently, it has been generally accepted that achieving a high ratio of $\mathrm{AUC}_{0-24} / \mathrm{MIC}$ would be more predictive of its clinical success. Studies by Moise-Broder et al were the earliest to quantify that a ratio of $\mathrm{AUC}_{0-24} / \mathrm{MIC}$ of $\geq 400$ is needed for an optimal bacteriological and clinical outcome when treating patients with $S$. aureus respiratory infections. ${ }^{35,127}$ The findings are consistent with the retrospective data evaluation of Zelenitsky et al and they also described that higher exposures are needed, specifically a ratio of $\mathrm{AUC}_{0-24} / \mathrm{MIC}$ of $\geq 578$, when treating critically ill patients with septic shock. ${ }^{128}$ Owing to common clinical practice of measuring trough concentrations when vancomycin is used, a trough concentration ranging between 15 and 20 $\mathrm{mg} / \mathrm{L}$ is recommended for optimal outcome in hospitalacquired pneumonia and complicated infections. ${ }^{129,130}$

Although scarce data exist, it could be assumed that the development of resistance is linked to suboptimal vancomycin exposure. Through their in vitro PD model, Tsuji et al were able to conclude that the development of vancomycin-intermediate susceptible $S$. aureus (VISA) strains was driven by suboptimal vancomycin exposure in the setting of dysfunctional agr locus in S. aureus. ${ }^{131}$ In addition, the investigators also found that the $\mathrm{AUC}_{0-24} / \mathrm{MIC}$ ratio needed to suppress resistance for the strains was fourfold higher than that in the parent strains. Charles et al observed that patients with VISA infections were more likely to present with low vancomycin trough concentrations (i.e., $<10 \mathrm{mg} / \mathrm{L}$ ). ${ }^{132}$ Based on similar findings to Charles et al's retrospective data evaluation, ${ }^{133,134}$ and considering the recommended trough concentrations for successful clinical outcomes in severe infections, vancomycin trough concentrations should also be maintained between $\geq 15$ and $20 \mathrm{mg} / \mathrm{L}$ at all times to suppress resistance emergence. $^{129}$ Thus, loading doses of 25 to $30 \mathrm{mg} / \mathrm{kg}$ should be considered in critically ill patients to rapidly attain the target concentration and certainly, higher vancomycin doses of up to $40 \mathrm{mg} / \mathrm{kg}$ may be important to minimize resistance development. In addition, doses in excess of $5 \mathrm{~g} /$ daily were estimated to be necessary to achieve the target $A_{U C-24}$ $\mathrm{MIC}$ ratio when treating VISA infections. ${ }^{135}$ Increasing knowledge of the relationship between higher vancomycin exposures and drug toxicities may limit the dosing of this drug to limit the emergence of resistance.

\section{Linezolid}

Linezolid belongs to a class of antibiotics known as oxazolidinones, which was developed for the treatment of grampositive infections. In a murine infection model, Andes et al demonstrated that optimal linezolid activity correlates well with the ratio of $\mathrm{AUC}_{0-24} / \mathrm{MIC}$, with a ratio of between 50 and 80 predicting the likelihood of successful treatment outcome. ${ }^{136}$ However, higher clinical success rates may occur at $\mathrm{AUC}_{0-24} / \mathrm{MIC}$ ratio of 80 to 120 for bacteremia, lower respiratory tract infections and skin structure infections as reported by Rayner et al. ${ }^{137}$ Importantly, the investigators also showed that the drug exposure required for optimal treatment outcome was also dependent on the site and types of infection. In addition, the probability of treatment success appeared likely when linezolid concentrations were maintained above the MIC for the entire dosing interval. The finding corroborated two earlier rabbit endocarditis experimental models, which described linezolid as a time-dependent antibiotic where an $f \mathrm{~T}_{>\text {MIC }}$ of $40 \%$ is needed for optimal antibiotic activity. ${ }^{136,138}$ A 600 -mg 12-hour dose is currently suggested to achieve these PD indices and hence, predicts successful treatment outcome. However, it is also imperative to emphasize that the antibiotic's PK is highly 
variable, ${ }^{27,115,139-141}$ particularly in patients with severe infections, and the phenomenon has, in part, contributed to treatment failures as well as the increased occurrence of adverse events in such patients. ${ }^{137,142}$ As such, therapeutic drug monitoring (TDM) of linezolid is beneficial in this respect and emerging data are suggesting that general TDM may optimize patient outcomes when linezolid is used in critically ill patients. In the context of antibiotic resistance, low-dose linezolid (200 mg 12 hourly) has been associated with the development of E. faecium and E. faecalis resistant strains. ${ }^{143}$ In addition, prior exposure and prolonged linezolid administration have been suggested to increase the likelihood of resistance development. ${ }^{144-146}$ Nevertheless, the development of resistance against the antibiotic has not been widely reported. ${ }^{147,148}$

\section{Daptomycin}

Daptomycin is the first approved member of the cyclic lipopeptides with a potent activity against gram-positive pathogens including methicillin-resistant S. aureus (MRSA) and vancomycin-resistant enterococci. In vivo experimental studies describe daptomycin to be a concentration-dependent antibiotic. The ratio of $\mathrm{C}_{\text {max }} / \mathrm{MIC}$ in concert with $\mathrm{AUC}_{0-24} / \mathrm{MIC}$ has been correlated with its efficacy in several in vivo animal studies. ${ }^{149-151}$ Safdar et al used a neutropenic murine thigh infection model to characterize the PD characteristics of the antibiotic. ${ }^{149}$ In the infection model, the $C_{\max } / \mathrm{MIC}$ and $\mathrm{AUC}_{0-24} / \mathrm{MIC}$ ratio required for bacteriostasis ranged from 59 to 94 and 388 to 537 (total drug concentration), respectively. Similar ratios were required for bacteriostasis in two other clinical studies, which recruited healthy volunteers. ${ }^{152,153}$ Based on these suggested indices, optimal daptomycin exposure could be expected in most patients with modest dosing (4-6 mg/kg/d). However, the emergence of daptomycin-resistant strains has been reported with such dosing regimens ${ }^{154,155}$ and some experts recommend the use of higher dosing to curb this issue (i.e., $8-12 \mathrm{mg} / \mathrm{kg} / \mathrm{d}$ ), ${ }^{156}$ which was shown to be safe in one retrospective data evaluation ${ }^{157}$ and several case reports. ${ }^{158,159}$ A duration of therapy exceeding 2 weeks has also been documented to increase the likelihood of daptomycin resistance. ${ }^{155}$

\section{Fosfomycin}

Fosfomycin, which was discovered more than 40 years ago but then forgotten, is a phosphonic acid derivative that possesses promising in vitro activity against carbapenemresistant K. pneumoniae. ${ }^{160}$ The introduction of fosfomycin into our current armamentarium of antibiotics was greeted with some skepticism due to major setbacks in its initial in vitro evaluation and this has, in part, contributed to its limited acceptance for clinical use. Although there are suggestions that fosfomycin's bacterial killing appears to be driven by $f \mathrm{~T}_{>\mathrm{MIC}}$, the optimal $\mathrm{PK} / \mathrm{PD}$ index relating to its activity remains to be established and requires further investigations. $^{161}$ In addition, rapid bacterial killing was observed in several static-time kill studies when drug concentrations were maintained at two to eight times the MIC. Similar to the $\beta$-lactams, the development of fosfomycin resistance is driven by low drug exposures and prolonged duration of antibiotic course. ${ }^{162}$ There has also been some debate concerning the rapid development of fosfomycin resistance when it is used as a monotherapy particularly in nonurinary tract infections. In a murine endocarditis model, Thauvin et al found that the combination of fosfomycin and pefloxacin was more effective in suppressing resistant $S$. aureus strains emergence when compared with fosfomycin alone. ${ }^{163}$ In several in vitro and in vivo experimental studies, instances of synergism were also demonstrated against MRSA when fosfomycin was combined with the $\beta$-lactams, ${ }^{164,165}$ linezolid, ${ }^{166}$ and moxifloxacin. ${ }^{167}$ Combining fosfomycin with $\beta$-lactams is also strongly supported by in vitro data, which describe synergism between the two antibiotics against $P$. aeruginosa infections. ${ }^{168-170}$ However, whether the in vitro synergism would translate to increased clinical efficacy remains to be demonstrated. In a recent prospective study, fosfomycin, in combination with colistin, gentamicin, or piperacillin/ tazobactam, provided promising bacteriological and clinical outcome data in the treatment of 11 critically ill patients with ICU-acquired infections caused by carbapenemresistant K. pneumoniae. ${ }^{171}$ Based on limited clinical data in treating serious infections in the ICU and its high tendency for developing resistance, fosfomycin should not be used as a single agent and the choice of adjunctive antibiotic should be appropriately evaluated in future studies.

\section{Colistin}

Colistin is a polymyxin antibiotic, which is administered parenterally as colistin methanesulfonate (CMS). The antibiotic has concentration-dependent kill characteristics with a significant in vitro PAE against gram-negative pathogens. ${ }^{172}$ In vivo murine studies suggested that the most predictive PD index for its bacterial activity, particularly against $A$. baumannii and $P$. aeruginosa, is $\mathrm{AUC}_{0-24} / \mathrm{MIC}{ }^{173,174}$ Based on observations in several lung infection models, the ratio of $\mathrm{AUC}_{0-24} / \mathrm{MIC}$ between 50 and 65 has been suggested as the optimal PD target, although higher exposures were also described in thigh infection models. ${ }^{175}$ The heteroresistance phenomenon, the situation whereby resistant subpopulations are present within a strain-considered susceptible based on MIC, is an emerging problem for the antibiotic and has been observed in clinical isolates of $A$. baumanii, ${ }^{176,177}$ K. pneumoniae, ${ }^{178}$ and P. aeruginosa. ${ }^{179}$ Further to this, rapid resistant mutants formation was demonstrated following colistin exposure in two recent in vitro PK/PD studies mimicking clinical dosing regimens in humans. ${ }^{180,181}$ This is particularly worrying as Garonzik et al suggested that the currently recommended CMS dosing regimen is suboptimal in a population PK analysis of 105 critically ill patients ${ }^{182}$ and their findings were corroborated by other investigators who recruited smaller number of patients. ${ }^{183,184}$ With increasing PK knowledge on the drug, Garonzik et $\mathrm{al}^{182}$ and Plachouras et $\mathrm{al}^{184}$ further described optimized CMS dosing regimens in patients with varying degrees of renal function. The dosing proposed by Plachouras et $\mathrm{al}^{184}$ has now been validated in a critical care setting by Dalfino et al in the 
treatment of MDR infections. ${ }^{185}$ Among the relevant recommendations concerning CMS dosing is the need for an initial loading dose, as the conversion of the prodrug CMS to the active entity of colistin is very slow and adequate colistin exposure may be delayed for a few days. Although theoretically plausible based on its PD characteristics, the adoption of EDD is not suitable on the basis of the resultant prolonged periods of low colistin concentrations leading to the formation of heteroresistance. ${ }^{173,174,180}$ Based on current PK data of critically ill patients ${ }^{182-184,186,187}$ and in vivo PK/PD experimental studies, ${ }^{173,174}$ colistin monotherapy would not be beneficial in maximizing therapeutic success and preventing resistance, particularly in patients with moderate-to-good renal function and for pathogens with MICs of $\geq 1$. In addition, a treatment course lasting more than 12 days has been found to be associated with the development of colistin resistance in two recent clinical studies. ${ }^{188,189}$

\section{Modifying Treatment Approaches to Prevent Emergence of Resistance}

\section{Combination Antibiotic Therapy}

Although combining antibiotics is common during the treatment of infection, the relevance of the practice has been the matter of debate with conflicting conclusions. Proponents of combination therapy will strongly suggest that the approach will increase antibiotic exposure via extending coverage across a wider range of potential pathogens and, in some clinical evaluations, has been found to improve survival in severely ill patients. ${ }^{190-193}$ Further strong theoretical reasons to seriously consider a combination antibiotic approach include antibiotic synergism which enhances killing potency; combined activity against biofilm-growing pathogens; increasing tissue penetration; inhibition of pathogen's toxin and enzyme production; and prevention of resistance development. However, there is also clinical evidence indicating that combination therapy may not be superior, even harmful in some instances, ${ }^{194-196}$ as opposed to monotherapy in the treatment of gram-negative bacilli infections. ${ }^{197-199}$ Based on the current data, it could be deduced that combination antibiotic therapy may not benefit all patients but rather a select patient population with select infections. While monotherapy may be sufficient for most patients, critically ill patients with severe infections may benefit the most from rationally optimized combination therapy. Although some in vitro infection models ${ }^{200,201}$ and animal studies ${ }^{202}$ clearly indicated benefits behind the approach, unfortunately, the vast majority of combination schemes were chosen randomly without considering the preclinical findings. ${ }^{203}$

In the context of resistance suppression, rationally optimized combination therapy may restrict the amplification of resistant mutants. Epstein et $\mathrm{al}^{204}$ suggest that the presence of more than two antibiotics at the infection loci (with drug concentrations above the MIC), each with a different killing mechanism, would "shut" the MSW and thereby suppress mutant growth. ${ }^{205-207}$ Apart from several preclinical stud- ies, ${ }^{53,200,202,208,209}$ no randomized clinical trials to date have shown that the approach reduces the emergence of resistance. Furthermore, the benefit is particularly difficult to be demonstrated in clinical evaluations, which frequently recruit heterogeneous patient population and are not conducted long enough to detect the emergence of resistance. In the face of rapidly evolving resistance phenomenon, it is likely that we have to turn our attention to the concept of rationally optimized combination antibiotic therapy, particularly in the treatment of severely ill patients in the ICU. In addition, the approach is likely to be important early in the course of infection when the inoculum of the infecting pathogens is the highest.

\section{Duration of Therapy}

It has been increasingly shown in preclinical studies that prolonged antibiotic administration may play an important role in the formation of resistant mutants. Conversely, the longer antibiotic therapy persists, the more challenging it is to curtail the emergence of resistant pathogens. It has been suggested that an antibiotic regimen that lasts for only 4 to 5 days should be sufficient to produce maximal bactericidal effect with an added benefit of resistance suppression. Extending antibiotic exposure to more than 10 days is risky on the basis of resistance development whereby higher drug exposures are needed to suppress resistant mutants in this situation and if this threshold is not achieved, treatment failure ensues as the resistant population dominates. This phenomenon has been described by Tam et al in their in vitro model of $S$. aureus infection which investigated two garenoxin dosing regimens with different intensity, one with an $\mathrm{AUC}_{0-24} / \mathrm{MIC}$ ratio of 280 and the other with $100 .{ }^{42}$ The investigators demonstrated that once the duration of garenoxin exposure increased beyond 5 days, the magnitude of dosing needed for suppressing resistant mutants also increased. The higher dosing regimen was found to suppress resistance amplification for 10 days, while the less intense regimen was only able to demonstrate the ability for 4 to 5 days.

At best, the common practice of administering an antibiotic for 10 to 14 days is currently based on limited data and expert opinion rather than it being an evidence-based approach. However, for some deep-seated infections such as osteomyelitis and endocarditis, prolonged antibiotic courses are essential. Instances of potential benefits from shortening the duration of antibiotic therapy in reducing the emergence of resistance while maintaining clinical efficacy have been increasingly described. ${ }^{210-213}$ Among these findings, Singh et al demonstrated that patients who received shortened antibiotic courses (i.e., $\leq 3$ days) had reduced ICU stays, lower superinfection and resistance rates, as well as lower mortality rates compared with patients who received standard courses. ${ }^{213}$ Further investigations are warranted to elucidate the exact duration of therapy that maximizes therapeutic outcome and suppresses resistance development. Until conclusive findings are made, antibiotic therapy should "hit hard" in the early course of infection and "stop early" to assist in resistance prevention. 


\section{Altered Dosing Approaches}

Optimal and timely PK/PD target attainment has been associated with the likelihood of clinical success and resistance suppression in critically ill patients. ${ }^{6}$ However, organ function changes that may result from either infectious or noninfectious pathologic processes may alter antibiotics exposure. For example, the increase in $\mathrm{V}_{\mathrm{d}}$ for hydrophilic antibiotics such as aminoglycosides, ${ }^{214,215} \beta$-lactams, ${ }^{216}$ glycopeptides, ${ }^{135}$ and linezolid, ${ }^{217}$ has been extensively documented in critically ill patients. Importantly, this phenomenon leads to suboptimal antibiotic concentration and may impair the attainment of desired PK/PD targets for optimal activity, particularly in the early phase of severe sepsis and septic shock. In this setting, higher initial loading doses of hydrophilic antibiotics should be applied to compensate for the volume expansion. In the context of resistance prevention, the approach may have the potential utility to rapidly reduce bacterial burden in the early stage of infection. Tsuji et al recently tested the impact of a front-loaded linezolid-dosing regimen on bacterial killing and resistance suppression in a HFIM of MRSA infection. ${ }^{218}$ From a PD standpoint of bacterial eradication, their findings suggest potential benefits of increasing doses of linezolid early in therapy, although no differences were observed in terms of resistance suppression. Further preclinical studies are necessary to investigate this promising dosing strategy particularly in the context of resistance suppression, before it can be fully applied in clinical practice.

For the $\beta$-lactams, maintaining effective exposure for extended periods or increasing $\% f \mathrm{~T}_{>\text {MIC }}$ would be especially appropriate in the prevention of resistance particularly in critically ill patients. Research has shown that the traditional bolus dosing produces suboptimal antibiotic concentrations for much of the dosing interval, which may consequently favor resistant bacterial strains development. ${ }^{109}$ Numerous preclinical and clinical PK/PD studies have demonstrated that improved $\beta$-lactams exposure could be achieved via $\mathrm{EI}$ or $\mathrm{Cl}$ administration. ${ }^{219}$ These altered dosing approaches may be especially important in patients who develop severe pathophysiological derangements and when less susceptible pathogens are present. However, more clinical studies are urgently needed to evaluate the relative ability of EI and CI versus IB dosing of $\beta$-lactam antibiotics in reducing the emergence of resistance if a global practice change is to be expected.

\section{Conclusion}

For decades now, clinicians have overused antibiotics and apparently did so with the notion that our continuous supply of new antibiotics would adequately address any emerging resistance concerns. That thought did not materialize and on the contrary, as our current antibiotic pipeline is nearly dry, infecting pathogens have tremendously outperformed our existing armamentarium thus far and they are becoming increasingly difficult to treat. The current situation that we are in is not surprising, as most of our treatment goals were previously focused on maximizing clinical and microbiological cure and not on minimization of the emergence of antibiotic resistance. With numerous preclinical data indicating that the magnitude of the PK/PD indices for resistance suppression is generally higher than the thresholds required for clinical success, antibiotic dosing that only aims to optimize clinical efficacy may potentially amplify resistance formation by selecting mutant bacterial strains with reduced drug susceptibility. Furthermore, the relevance of commonly prescribed antibiotic dosing is questionable in severely ill patients as most dosing recommendations have been derived from studies that do not consider the occurrence of pathophysiological changes in critical illness. Therefore, with enhanced knowledge on antibiotic PK/PD over recent years, emerging data are suggesting that the PD-based dosing approach should not only aim to maximize clinical outcomes but also to include the suppression of resistance. In some antibiotics such as the quinolones, the PD thresholds needed to prevent the emergence of resistance is readily described but, unfortunately, is often neglected and not implemented in clinical practice, while for most antibiotic classes specific research is urgently needed. To curb the development of resistance, it is likely that we have to administer "the highest tolerated antibiotic dose" via alternative dosing strategies and should also consider the combined use of multiple antibiotics (that are rationally optimized), particularly early in the course of infection in severely ill patients.

Financial Support

None.

Conflict of Interest

None.

Acknowledgment

Jason Roberts is funded by a Career Development Fellowship from the National Health and Medical Research Council of Australia (APP1048652).

\section{References}

1 Vincent JL, Rello J, Marshall J, et al; EPIC II Group of Investigators. International study of the prevalence and outcomes of infection in intensive care units. JAMA 2009;302(21):2323-2329

2 Vincent JL, Sakr Y, Sprung CL, et al; Sepsis Occurrence in Acutely Ill Patients Investigators. Sepsis in European intensive care units: results of the SOAP study. Crit Care Med 2006;34(2):344-353

3 Kaukonen KM, Bailey M, Suzuki S, Pilcher D, Bellomo R. Mortality related to severe sepsis and septic shock among critically ill patients in Australia and New Zealand, 2000-2012. JAMA 2014; 311(13):1308-1316

4 Stevenson EK, Rubenstein AR, Radin GT, Wiener RS, Walkey AJ. Two decades of mortality trends among patients with severe sepsis: a comparative meta-analysis. Crit Care Med 2014;42(3): 625-631

5 ARISE; ANZICS APD Management Committee. The outcome of patients with sepsis and septic shock presenting to emergency departments in Australia and New Zealand. Crit Care Resusc 2007;9(1):8-18 
6 Dellinger RP, Levy MM, Rhodes A, et al; Surviving Sepsis Campaign Guidelines Committee including the Pediatric Subgroup. Surviving sepsis campaign: international guidelines for management of severe sepsis and septic shock: 2012. Crit Care Med 2013; 41(2):580-637

7 Coopersmith CM, Wunsch H, Fink MP, et al. A comparison of critical care research funding and the financial burden of critical illness in the United States. Crit Care Med 2012;40(4):1072-1079

8 Ranieri VM, Thompson BT, Barie PS, et al; PROWESS-SHOCK Study Group. Drotrecogin alfa (activated) in adults with septic shock. N Engl J Med 2012;366(22):2055-2064

9 Warren BL, Eid A, Singer P, et al; KyberSept Trial Study Group. Caring for the critically ill patient. High-dose antithrombin III in severe sepsis: a randomized controlled trial.JAMA 2001;286(15): 1869-1878

10 Finfer S, Chittock DR, Su SY, et al; NICE-SUGAR Study Investigators. Intensive versus conventional glucose control in critically ill patients. N Engl J Med 2009;360(13):1283-1297

11 Garnacho-Montero J, Aldabo-Pallas T, Garnacho-Montero C, et al. Timing of adequate antibiotic therapy is a greater determinant of outcome than are TNF and IL-10 polymorphisms in patients with sepsis. Crit Care 2006;10(4):R111

12 Kumar A, Roberts D, Wood KE, et al. Duration of hypotension before initiation of effective antimicrobial therapy is the critical determinant of survival in human septic shock. Crit Care Med 2006;34(6):1589-1596

13 Garnacho-Montero J, Garcia-Garmendia JL, Barrero-Almodovar A, Jimenez-Jimenez FJ, Perez-Paredes C, Ortiz-Leyba C. Impact of adequate empirical antibiotic therapy on the outcome of patients admitted to the intensive care unit with sepsis. Crit Care Med 2003;31(12):2742-2751

14 Felton TW, Hope WW, Roberts JA. How severe is antibiotic pharmacokinetic variability in critically ill patients and what can be done about it? Diagn Microbiol Infect Dis 2014;79(4): 441-447

15 Zhanel GG, DeCorby M, Laing N, et al; Canadian Antimicrobial Resistance Alliance (CARA). Antimicrobial-resistant pathogens in intensive care units in Canada: results of the Canadian National Intensive Care Unit (CAN-ICU) study, 2005-2006. Antimicrob Agents Chemother 2008;52(4):1430-1437

16 Rhomberg PR, Fritsche TR, Sader HS, Jones RN. Antimicrobial susceptibility pattern comparisons among intensive care unit and general ward Gram-negative isolates from the Meropenem Yearly Susceptibility Test Information Collection Program (USA). Diagn Microbiol Infect Dis 2006;56(1):57-62

17 Mouton JW, Ambrose PG, Canton R, et al. Conserving antibiotics for the future: new ways to use old and new drugs from a pharmacokinetic and pharmacodynamic perspective. Drug Resist Updat 2011;14(2):107-117

18 Dulhunty JM, Paterson D, Webb SA, Lipman J. Antimicrobial utilisation in 37 Australian and New Zealand intensive care units. Anaesth Intensive Care 2011;39(2):231-237

19 Singh N, Yu VL. Rational empiric antibiotic prescription in the ICU. Chest 2000;117(5):1496-1499

20 Fridkin SK, Gaynes RP. Antimicrobial resistance in intensive care units. Clin Chest Med 1999;20(2):303-316, viii

21 Livermore DM. Fourteen years in resistance. Int J Antimicrob Agents 2012;39(4):283-294

22 Ben-David D, Kordevani R, Keller N, et al. Outcome of carbapenem resistant Klebsiella pneumoniae bloodstream infections. Clin Microbiol Infect 2012;18(1):54-60

23 Lye DC, Earnest A, Ling ML, et al. The impact of multidrug resistance in healthcare-associated and nosocomial Gram-negative bacteraemia on mortality and length of stay: cohort study. Clin Microbiol Infect 2012;18(5):502-508

24 Shorr AF. Review of studies of the impact on Gram-negative bacterial resistance on outcomes in the intensive care unit. Crit Care Med 2009;37(4):1463-1469
25 Roberts JA, Kruger P, Paterson DL, Lipman J. Antibiotic resistancewhat's dosing got to do with it? Crit Care Med 2008;36(8): 2433-2440

26 Roberts JA, Abdul-Aziz MH, Lipman J, et al; International Society of Anti-Infective Pharmacology and the Pharmacokinetics and Pharmacodynamics Study Group of the European Society of Clinical Microbiology and Infectious Diseases. Individualised antibiotic dosing for patients who are critically ill: challenges and potential solutions. Lancet Infect Dis 2014;14(6):498-509

27 Zeitlinger MA, Derendorf H, Mouton JW, et al. Protein binding: do we ever learn? Antimicrob Agents Chemother 2011;55(7): 3067-3074

28 Drusano GL. Pharmacokinetics and pharmacodynamics of antimicrobials. Clin Infect Dis 2007;45(1, Suppl 1):S89-S95

29 Mouton JW, Jacobs N, Tiddens H, Horrevorts AM. Pharmacodynamics of tobramycin in patients with cystic fibrosis. Diagn Microbiol Infect Dis 2005;52(2):123-127

30 Craig WA. Pharmacokinetic/pharmacodynamic parameters: rationale for antibacterial dosing of mice and men. Clin Infect Dis 1998;26(1):1-10, quiz 11-12

31 Craig WA, Redington J, Ebert SC. Pharmacodynamics of amikacin in vitro and in mouse thigh and lung infections. J Antimicrob Chemother 1991;27(Suppl C):29-40

32 Moore RD, Lietman PS, Smith CR. Clinical response to aminoglycoside therapy: importance of the ratio of peak concentration to minimal inhibitory concentration. J Infect Dis 1987;155(1): 93-99

33 McKinnon PS, Paladino JA, Schentag JJ. Evaluation of area under the inhibitory curve (AUIC) and time above the minimum inhibitory concentration ( $\mathrm{T}>\mathrm{MIC}$ ) as predictors of outcome for cefepime and ceftazidime in serious bacterial infections. Int J Antimicrob Agents 2008;31(4):345-351

34 Craig WA. Basic pharmacodynamics of antibacterials with clinical applications to the use of beta-lactams, glycopeptides, and linezolid. Infect Dis Clin North Am 2003;17(3):479-501

35 Moise-Broder PA, Forrest A, Birmingham MC, Schentag JJ. Pharmacodynamics of vancomycin and other antimicrobials in patients with Staphylococcus aureus lower respiratory tract infections. Clin Pharmacokinet 2004;43(13):925-942

36 Firsov AA, Strukova EN, Shlykova DS, et al. Bacterial resistance studies using in vitro dynamic models: the predictive power of the mutant prevention and minimum inhibitory antibiotic concentrations. Antimicrob Agents Chemother 2013;57(10): 4956-4962

37 Tam VH, Louie A, Deziel MR, Liu W, Drusano GL. The relationship between quinolone exposures and resistance amplification is characterized by an inverted U: a new paradigm for optimizing pharmacodynamics to counterselect resistance. Antimicrob Agents Chemother 2007;51(2):744-747

38 Tam VH, Louie A, Deziel MR, Liu W, Leary R, Drusano GL. Bacterial-population responses to drug-selective pressure: examination of garenoxacin's effect on Pseudomonas aeruginosa. J Infect Dis 2005;192(3):420-428

39 Firsov AA, Vostrov SN, Lubenko IY, Drlica K, Portnoy YA, Zinner $\mathrm{SH}$. In vitro pharmacodynamic evaluation of the mutant selection window hypothesis using four fluoroquinolones against Staphylococcus aureus. Antimicrob Agents Chemother 2003;47(5): 1604-1613

40 Stearne LE, Goessens WH, Mouton JW, Gyssens IC. Effect of dosing and dosing frequency on the efficacy of ceftizoxime and the emergence of ceftizoxime resistance during the early development of murine abscesses caused by Bacteroides fragilis and Enterobacter cloacae mixed infection. Antimicrob Agents Chemother 2007;51(10):3605-3611

41 Jumbe N, Louie A, Leary R, et al. Application of a mathematical model to prevent in vivo amplification of antibiotic-resistant bacterial populations during therapy. J Clin Invest 2003;112(2): 275-285 
42 Tam VH, Louie A, Fritsche TR, et al. Impact of drug-exposure intensity and duration of therapy on the emergence of Staphylococcus aureus resistance to a quinolone antimicrobial. J Infect Dis 2007;195(12):1818-1827

43 LaPlante KL, Rybak MJ, Tsuji B, Lodise TP, Kaatz GW. Fluoroquinolone resistance in Streptococcus pneumoniae: area under the concentration-time curve/MIC ratio and resistance development with gatifloxacin, gemifloxacin, levofloxacin, and moxifloxacin. Antimicrob Agents Chemother 2007;51(4):1315-1320

44 Tam VH, Schilling AN, Neshat S, Poole K, Melnick DA, Coyle EA. Optimization of meropenem minimum concentration/MIC ratio to suppress in vitro resistance of Pseudomonas aeruginosa. Antimicrob Agents Chemother 2005;49(12):4920-4927

45 Drusano GL, Bonomo RA, Bahniuk N, et al. Resistance emergence mechanism and mechanism of resistance suppression by tobramycin for cefepime for Pseudomonas aeruginosa. Antimicrob Agents Chemother 2012;56(1):231-242

46 Gumbo T, Louie A, Deziel MR, Parsons LM, Salfinger M, Drusano GL. Selection of a moxifloxacin dose that suppresses drug resistance in Mycobacterium tuberculosis, by use of an in vitro pharmacodynamic infection model and mathematical modeling. J Infect Dis 2004;190(9):1642-1651

47 Baquero F, Negri MC. Strategies to minimize the development of antibiotic resistance. J Chemother 1997;9(Suppl 3):29-37

48 Baquero F. Resistance to quinolones in gram-negative microorganisms: mechanisms and prevention. Eur Urol 1990;17 (Suppl 1):3-12

49 Zhao X, Drlica K. Restricting the selection of antibiotic-resistant mutants: a general strategy derived from fluoroquinolone studies. Clin Infect Dis 2001;33(3, Suppl 3):S147-S156

50 Dong Y, Zhao X, Kreiswirth BN, Drlica K. Mutant prevention concentration as a measure of antibiotic potency: studies with clinical isolates of Mycobacterium tuberculosis. Antimicrob Agents Chemother 2000;44(9):2581-2584

51 Dong Y, Zhao X, Domagala J, Drlica K. Effect of fluoroquinolone concentration on selection of resistant mutants of Mycobacterium bovis BCG and Staphylococcus aureus. Antimicrob Agents Chemother 1999;43(7):1756-1758

52 Zhou J, Dong Y, Zhao X, et al. Selection of antibiotic-resistant bacterial mutants: allelic diversity among fluoroquinolone-resistant mutations. J Infect Dis 2000;182(2):517-525

53 Firsov AA, Smirnova MV, Lubenko IY, Vostrov SN, Portnoy YA, Zinner SH. Testing the mutant selection window hypothesis with Staphylococcus aureus exposed to daptomycin and vancomycin in an in vitro dynamic model. J Antimicrob Chemother 2006;58(6): 1185-1192

54 Campion JJ, Chung P, McNamara PJ, Titlow WB, Evans ME. Pharmacodynamic modeling of the evolution of levofloxacin resistance in Staphylococcus aureus. Antimicrob Agents Chemother 2005;49(6):2189-2199

55 Zinner SH, Lubenko IY, Gilbert D, et al. Emergence of resistant Streptococcus pneumoniae in an in vitro dynamic model that simulates moxifloxacin concentrations inside and outside the mutant selection window: related changes in susceptibility, resistance frequency and bacterial killing. J Antimicrob Chemother 2003;52(4):616-622

56 Cui J, Liu Y, Wang R, Tong W, Drlica K, Zhao X. The mutant selection window in rabbits infected with Staphylococcus aureus. J Infect Dis 2006;194(11):1601-1608

57 Croisier D, Etienne M, Piroth L, et al. In vivo pharmacodynamic efficacy of gatifloxacin against Streptococcus pneumoniae in an experimental model of pneumonia: impact of the low levels of fluoroquinolone resistance on the enrichment of resistant mutants. J Antimicrob Chemother 2004;54(3):640-647

58 Etienne M, Croisier D, Charles PE, et al. Effect of low-level resistance on subsequent enrichment of fluoroquinolone-resistant Streptococcus pneumoniae in rabbits. J Infect Dis 2004; 190(8):1472-1475
59 Andes D, Craig WA. Pharmacodynamics of the new fluoroquinolone gatifloxacin in murine thigh and lung infection models. Antimicrob Agents Chemother 2002;46(6):1665-1670

60 Olofsson SK, Marcusson LL, Komp Lindgren P, Hughes D, Cars O. Selection of ciprofloxacin resistance in Escherichia coli in an in vitro kinetic model: relation between drug exposure and mutant prevention concentration. J Antimicrob Chemother 2006;57(6): 1116-1121

61 Croisier D, Etienne M, Bergoin E, et al. Mutant selection window in levofloxacin and moxifloxacin treatments of experimental pneumococcal pneumonia in a rabbit model of human therapy. Antimicrob Agents Chemother 2004;48(5):1699-1707

62 Knudsen JD, Odenholt I, Erlendsdottir H, et al. Selection of resistant Streptococcus pneumoniae during penicillin treatment in vitro and in three animal models. Antimicrob Agents Chemother 2003;47(8):2499-2506

63 Liang B, Bai N, Cai Y, Wang R, Drlica K, Zhao X. Mutant prevention concentration-based pharmacokinetic/pharmacodynamic indices as dosing targets for suppressing the enrichment of levofloxacin-resistant subpopulations of Staphylococcus aureus. Antimicrob Agents Chemother 2011;55(5):2409-2412

64 Firsov AA, Smirnova MV, Strukova EN, Vostrov SN, Portnoy YA, Zinner SH. Enrichment of resistant Staphylococcus aureus at ciprofloxacin concentrations simulated within the mutant selection window: bolus versus continuous infusion. Int J Antimicrob Agents 2008;32(6):488-493

65 Firsov AA, Vostrov SN, Lubenko IY, Arzamastsev AP, Portnoy YA, Zinner SH. ABT492 and levofloxacin: comparison of their pharmacodynamics and their abilities to prevent the selection of resistant Staphylococcus aureus in an in vitro dynamic model. J Antimicrob Chemother 2004;54(1):178-186

66 Gugel J, Dos Santos Pereira A, Pignatari AC, Gales AC. beta-Lactam MICs correlate poorly with mutant prevention concentrations for clinical isolates of Acinetobacter spp. and Pseudomonas aeruginosa. Antimicrob Agents Chemother 2006;50(6):2276-2277

67 Hansen GT, Metzler K, Drlica K, Blondeau JM. Mutant prevention concentration of gemifloxacin for clinical isolates of Streptococcus pneumoniae. Antimicrob Agents Chemother 2003;47(1): 440-441

68 Drusano GL, Johnson DE, Rosen M, Standiford HC. Pharmacodynamics of a fluoroquinolone antimicrobial agent in a neutropenic rat model of Pseudomonas sepsis. Antimicrob Agents Chemother 1993;37(3):483-490

69 Blaser J, Stone BB, Groner MC, Zinner SH. Comparative study with enoxacin and netilmicin in a pharmacodynamic model to determine importance of ratio of antibiotic peak concentration to MIC for bactericidal activity and emergence of resistance. Antimicrob Agents Chemother 1987;31(7):1054-1060

70 Thorburn CE, Edwards DI. The effect of pharmacokinetics on the bactericidal activity of ciprofloxacin and sparfloxacin against Streptococcus pneumoniae and the emergence of resistance. J Antimicrob Chemother 2001;48(1):15-22

71 Forrest A, Nix DE, Ballow CH, Goss TF, Birmingham MC, Schentag JJ. Pharmacodynamics of intravenous ciprofloxacin in seriously ill patients. Antimicrob Agents Chemother 1993;37(5): 1073-1081

72 Peloquin CA, Cumbo TJ, Nix DE, Sands MF, Schentag JJ. Evaluation of intravenous ciprofloxacin in patients with nosocomial lower respiratory tract infections. Impact of plasma concentrations, organism, minimum inhibitory concentration, and clinical condition on bacterial eradication. Arch Intern Med 1989;149(10): 2269-2273

73 Zelenitsky SA, Ariano RE. Support for higher ciprofloxacin AUC 24/MIC targets in treating Enterobacteriaceae bloodstream infection. J Antimicrob Chemother 2010;65(8):1725-1732

74 Drusano GL, Preston SL, Fowler C, Corrado M, Weisinger B, Kahn J. Relationship between fluoroquinolone area under the curve: minimum inhibitory concentration ratio and the probability of 
eradication of the infecting pathogen, in patients with nosocomial pneumonia. J Infect Dis 2004;189(9):1590-1597

75 Ambrose PG, Grasela DM, Grasela TH, Passarell J, Mayer HB, Pierce PF. Pharmacodynamics of fluoroquinolones against Streptococcus pneumoniae in patients with community-acquired respiratory tract infections. Antimicrob Agents Chemother 2001;45(10): 2793-2797

76 Mattoes HM, Banevicius M, Li D, et al. Pharmacodynamic assessment of gatifloxacin against Streptococcus pneumoniae. Antimicrob Agents Chemother 2001;45(7):2092-2097

77 Bédos JP, Azoulay-Dupuis E, Moine P, et al. Pharmacodynamic activities of ciprofloxacin and sparfloxacin in a murine pneumococcal pneumonia model: relevance for drug efficacy. J Pharmacol Exp Ther 1998;286(1):29-35

78 Thomas JK, Forrest A, Bhavnani SM, et al. Pharmacodynamic evaluation of factors associated with the development of bacterial resistance in acutely ill patients during therapy. Antimicrob Agents Chemother 1998;42(3):521-527

79 Schentag JJ, Gilliland KK, Paladino JA. What have we learned from pharmacokinetic and pharmacodynamic theories? Clin Infect Dis 2001;32(1, Suppl 1):S39-S46

80 Burgess DS, Hall RG II. Simulated comparison of the pharmacodynamics of ciprofloxacin and levofloxacin against Pseudomonas aeruginosa using pharmacokinetic data from healthy volunteers and 2002 minimum inhibitory concentration data. Clin Ther 2007;29(7):1421-1427

81 Gebru E, Choi MJ, Lee SJ, Damte D, Park SC. Mutant-prevention concentration and mechanism of resistance in clinical isolates and enrofloxacin/marbofloxacin-selected mutants of Escherichia coli of canine origin. J Med Microbiol 2011;60(Pt 10):1512-1522

82 Firsov AA, Vostrov SN, Lubenko IY, Zinner SH, Portnoy YA. Concentration-dependent changes in the susceptibility and killing of Staphylococcus aureus in an in vitro dynamic model that simulates normal and impaired gatifloxacin elimination. Int $\mathrm{J}$ Antimicrob Agents 2004;23(1):60-66

83 Khachman D, Conil JM, Georges B, et al. Optimizing ciprofloxacin dosing in intensive care unit patients through the use of population pharmacokinetic-pharmacodynamic analysis and Monte Carlo simulations. J Antimicrob Chemother 2011;66(8): 1798-1809

84 MacArthur RD, Lolans V, Zar FA, Jackson GG. Biphasic, concentration-dependent and rate-limited, concentration-independent bacterial killing by an aminoglycoside antibiotic. J Infect Dis 1984;150(5):778-779

85 Mouton JW, Vinks AA. Pharmacokinetic/pharmacodynamic modelling of antibacterials in vitro and in vivo using bacterial growth and kill kinetics: the minimum inhibitory concentration versus stationary concentration. Clin Pharmacokinet 2005;44(2): 201-210

86 Vogelman B, Gudmundsson S, Leggett J, Turnidge J, Ebert S, Craig WA. Correlation of antimicrobial pharmacokinetic parameters with therapeutic efficacy in an animal model. J Infect Dis 1988; 158(4):831-847

87 Kashuba AD, Nafziger AN, Drusano GL, Bertino JS Jr. Optimizing aminoglycoside therapy for nosocomial pneumonia caused by gram-negative bacteria. Antimicrob Agents Chemother 1999; 43(3):623-629

88 Zelenitsky SA, Harding GK, Sun S, Ubhi K, Ariano RE. Treatment and outcome of Pseudomonas aeruginosa bacteraemia: an antibiotic pharmacodynamic analysis. J Antimicrob Chemother 2003; 52(4):668-674

89 Drusano GL, Ambrose PG, Bhavnani SM, Bertino JS, Nafziger AN, Louie A. Back to the future: using aminoglycosides again and how to dose them optimally. Clin Infect Dis 2007;45(6):753-760

90 Smith PF, Ballow CH, Booker BM, Forrest A, Schentag JJ. Pharmacokinetics and pharmacodynamics of aztreonam and tobramycin in hospitalized patients. Clin Ther 2001;23(8):1231-1244
91 Xiong YQ Caillon J, Kergueris MF, et al. Adaptive resistance of Pseudomonas aeruginosa induced by aminoglycosides and killing kinetics in a rabbit endocarditis model. Antimicrob Agents Chemother 1997;41(4):823-826

92 Barclay ML, Begg EJ, Chambers ST. Adaptive resistance following single doses of gentamicin in a dynamic in vitro model. Antimicrob Agents Chemother 1992;36(9):1951-1957

93 Daikos GL, Lolans VT, Jackson GG. First-exposure adaptive resistance to aminoglycoside antibiotics in vivo with meaning for optimal clinical use. Antimicrob Agents Chemother 1991;35(1): 117-123

94 Tam VH, Ledesma KR, Vo G, Kabbara S, Lim TP, Nikolaou M. Pharmacodynamic modeling of aminoglycosides against Pseudomonas aeruginosa and Acinetobacter baumannii: identifying dosing regimens to suppress resistance development. Antimicrob Agents Chemother 2008;52(11):3987-3993

95 Marik PE, Lipman J, Kobilski S, Scribante J. A prospective randomized study comparing once- versus twice-daily amikacin dosing in critically ill adult and paediatric patients. J Antimicrob Chemother 1991;28(5):753-764

96 Prins JM, Büller HR, Kuijper EJ, Tange RA, Speelman P. Once versus thrice daily gentamicin in patients with serious infections. Lancet 1993;341(8841):335-339

97 Bailey TC, Little JR, Littenberg B, Reichley RM, Dunagan WC. A meta-analysis of extended-interval dosing versus multiple daily dosing of aminoglycosides. Clin Infect Dis 1997;24(5):786-795

98 Munckhof WJ, Grayson ML, Turnidge JD. A meta-analysis of studies on the safety and efficacy of aminoglycosides given either once daily or as divided doses. J Antimicrob Chemother 1996; 37(4):645-663

99 Crandon JL, Bulik CC, Kuti JL, Nicolau DP. Clinical pharmacodynamics of cefepime in patients infected with Pseudomonas aeruginosa. Antimicrob Agents Chemother 2010;54(3):1111-1116

100 Mouton JW, Punt N, Vinks AA. Concentration-effect relationship of ceftazidime explains why the time above the MIC is 40 percent for a static effect in vivo. Antimicrob Agents Chemother 2007; 51(9):3449-3451

101 Ong CT, Tessier PR, Li C, Nightingale CH, Nicolau DP. Comparative in vivo efficacy of meropenem, imipenem, and cefepime against Pseudomonas aeruginosa expressing MexA-MexB-OprM efflux pumps. Diagn Microbiol Infect Dis 2007;57(2):153-161

102 Muller AE, Punt N, Mouton JW. Exposure to ceftobiprole is associated with microbiological eradication and clinical cure in patients with nosocomial pneumonia. Antimicrob Agents Chemother 2014;58(5):2512-2519

103 Muller AE, Punt N, Mouton JW. Optimal exposures of ceftazidime predict the probability of microbiological and clinical outcome in the treatment of nosocomial pneumonia. J Antimicrob Chemother 2013;68(4):900-906

104 Roberts JA, Paul SK, Akova M, et al; DALI Study. DALI: defining antibiotic levels in intensive care unit patients: are current $\beta$ lactam antibiotic doses sufficient for critically ill patients? Clin Infect Dis 2014;58(8):1072-1083

105 Ariano RE, Nyhlén A, Donnelly JP, Sitar DS, Harding GK, Zelenitsky SA. Pharmacokinetics and pharmacodynamics of meropenem in febrile neutropenic patients with bacteremia. Ann Pharmacother 2005;39(1):32-38

106 Mouton JW, den Hollander JG. Killing of Pseudomonas aeruginosa during continuous and intermittent infusion of ceftazidime in an in vitro pharmacokinetic model. Antimicrob Agents Chemother 1994;38(5):931-936

107 Li C, Du X, Kuti JL, Nicolau DP. Clinical pharmacodynamics of meropenem in patients with lower respiratory tract infections. Antimicrob Agents Chemother 2007;51(5):1725-1730

108 Tam VH, McKinnon PS, Akins RL, Rybak MJ, Drusano GL. Pharmacodynamics of cefepime in patients with Gram-negative infections. J Antimicrob Chemother 2002;50(3):425-428 
109 Abdul-Aziz MH, Dulhunty JM, Bellomo R, Lipman J, Roberts JA. Continuous beta-lactam infusion in critically ill patients: the clinical evidence. Ann Intensive Care 2012;2(1):37

110 Fantin B, Farinotti R, Thabaut A, Carbon C. Conditions for the emergence of resistance to cefpirome and ceftazidime in experimental endocarditis due to Pseudomonas aeruginosa. J Antimicrob Chemother 1994;33(3):563-569

111 Olofsson SK, Geli P, Andersson DI, Cars O. Pharmacodynamic model to describe the concentration-dependent selection of cefotaxime-resistant Escherichia coli. Antimicrob Agents Chemother 2005;49(12):5081-5091

112 Goessens WH, Mouton JW, ten Kate MT, Bijl AJ, Ott A, BakkerWoudenberg IA. Role of ceftazidime dose regimen on the selection of resistant Enterobacter cloacae in the intestinal flora of rats treated for an experimental pulmonary infection. J Antimicrob Chemother 2007;59(3):507-516

113 Tam VH, Schilling AN, Melnick DA, Coyle EA. Comparison of betalactams in counter-selecting resistance of Pseudomonas aeruginosa. Diagn Microbiol Infect Dis 2005;52(2):145-151

114 Gudmundsson S, Vogelman B, Craig WA. The in-vivo postantibiotic effect of imipenem and other new antimicrobials. J Antimicrob Chemother 1986;18(Suppl E):67-73

115 Fuentes F, Martín MM, Izquierdo J, Gomez-Lus ML, Prieto J. In vivo and in vitro study of several pharmacodynamic effects of meropenem. Scand J Infect Dis 1995;27(5):469-474

116 Tam VH, Ledesma KR, Schilling AN, et al. In vivo dynamics of carbapenem-resistant Pseudomonas aeruginosa selection after suboptimal dosing. Diagn Microbiol Infect Dis 2009;64(4): 427-433

117 Zinner SH, Gilbert D, Greer K, Portnoy YA, Firsov AA. Concentration-resistance relationships with Pseudomonas aeruginosa exposed to doripenem and ciprofloxacin in an in vitro model. J Antimicrob Chemother 2013;68(4):881-887

118 Roberts JA, Kirkpatrick CM, Roberts MS, Robertson TA, Dalley AJ, Lipman J. Meropenem dosing in critically ill patients with sepsis and without renal dysfunction: intermittent bolus versus continuous administration? Monte Carlo dosing simulations and subcutaneous tissue distribution. J Antimicrob Chemother 2009;64(1):142-150

119 Lorente L, Lorenzo L, Martín MM, Jiménez A, Mora ML. Meropenem by continuous versus intermittent infusion in ventilatorassociated pneumonia due to gram-negative bacilli. Ann Pharmacother 2006;40(2):219-223

120 Krueger WA, Bulitta J, Kinzig-Schippers M, et al. Evaluation by monte carlo simulation of the pharmacokinetics of two doses of meropenem administered intermittently or as a continuous infusion in healthy volunteers. Antimicrob Agents Chemother 2005;49(5):1881-1889

121 Louie A, Bied A, Fregeau C, et al. Impact of different carbapenems and regimens of administration on resistance emergence for three isogenic Pseudomonas aeruginosa strains with differing mechanisms of resistance. Antimicrob Agents Chemother 2010; 54(6):2638-2645

122 Chastre J, Wunderink R, Prokocimer P, Lee M, Kaniga K, Friedland I. Efficacy and safety of intravenous infusion of doripenem versus imipenem in ventilator-associated pneumonia: a multicenter, randomized study. Crit Care Med 2008;36(4):1089-1096

123 Löwdin E, Odenholt I, Cars O. In vitro studies of pharmacodynamic properties of vancomycin against Staphylococcus aureus and Staphylococcus epidermidis. Antimicrob Agents Chemother 1998;42(10):2739-2744

124 Larsson AJ, Walker KJ, Raddatz JK, Rotschafer JC. The concentration-independent effect of monoexponential and biexponential decay in vancomycin concentrations on the killing of Staphylococcus aureus under aerobic and anaerobic conditions. J Antimicrob Chemother 1996;38(4):589-597

125 Chambers HF, Kennedy S. Effects of dosage, peak and trough concentrations in serum, protein binding, and bactericidal rate on efficacy of teicoplanin in a rabbit model of endocarditis. Antimicrob Agents Chemother 1990;34(4):510-514

126 Knudsen JD, Fuursted K, Raber S, Espersen F, Frimodt-Moller N. Pharmacodynamics of glycopeptides in the mouse peritonitis model of Streptococcus pneumoniae or Staphylococcus aureus infection. Antimicrob Agents Chemother 2000;44(5):1247-1254

127 Moise PA, Forrest A, Bhavnani SM, Birmingham MC, Schentag JJ. Area under the inhibitory curve and a pneumonia scoring system for predicting outcomes of vancomycin therapy for respiratory infections by Staphylococcus aureus. Am J Health Syst Pharm 2000;57(2, Suppl 2):S4-S9

128 Zelenitsky S, Rubinstein E, Ariano R, et al; Cooperative Antimicrobial Therapy of Septic Shock-CATSS Database Research Group. Vancomycin pharmacodynamics and survival in patients with methicillin-resistant Staphylococcus aureus-associated septic shock. Int J Antimicrob Agents 2013;41(3):255-260

129 Rybak MJ, Lomaestro BM, Rotschafer JC, et al. Vancomycin therapeutic guidelines: a summary of consensus recommendations from the infectious diseases Society of America, the American Society of Health-System Pharmacists, and the Society of Infectious Diseases Pharmacists. Clin Infect Dis 2009;49(3):325-327

130 American Thoracic Society; Infectious Diseases Society of America. Guidelines for the management of adults with hospitalacquired, ventilator-associated, and healthcare-associated pneumonia. Am J Respir Crit Care Med 2005;171(4):388-416

131 Tsuji BT, Rybak MJ, Lau KL, Sakoulas G. Evaluation of accessory gene regulator (agr) group and function in the proclivity towards vancomycin intermediate resistance in Staphylococcus aureus. Antimicrob Agents Chemother 2007;51(3):1089-1091

132 Charles PG, Ward PB, Johnson PD, Howden BP, Grayson ML. Clinical features associated with bacteremia due to heterogeneous vancomycin-intermediate Staphylococcus aureus. Clin Infect Dis 2004;38(3):448-451

133 Sakoulas G, Gold HS, Cohen RA, Venkataraman L, Moellering RC, Eliopoulos GM. Effects of prolonged vancomycin administration on methicillin-resistant Staphylococcus aureus (MRSA) in a patient with recurrent bacteraemia. J Antimicrob Chemother 2006; 57(4):699-704

134 Howden BP, Ward PB, Charles PG, et al. Treatment outcomes for serious infections caused by methicillin-resistant Staphylococcus aureus with reduced vancomycin susceptibility. Clin Infect Dis 2004;38(4):521-528

135 del Mar Fernández de Gatta Garcia M, Revilla N, Calvo MV, Domínguez-Gil A, Sánchez Navarro A. Pharmacokinetic/pharmacodynamic analysis of vancomycin in ICU patients. Intensive Care Med 2007;33(2):279-285

136 Andes D, van Ogtrop ML, Peng J, Craig WA. In vivo pharmacodynamics of a new oxazolidinone (linezolid). Antimicrob Agents Chemother 2002;46(11):3484-3489

137 Rayner CR, Forrest A, Meagher AK, Birmingham MC, Schentag JJ. Clinical pharmacodynamics of linezolid in seriously ill patients treated in a compassionate use programme. Clin Pharmacokinet 2003;42(15):1411-1423

138 Buchanan LV, Dailey CF, LeMay RJ, Zielinski RJ, Kuo MS, Gibson JK. Time-dependent antibacterial effects of linezolid in experimental rabbit endocarditis. J Antimicrob Chemother 2002;50(3): 440-442

139 Zoller M, Maier B, Hornuss C, et al. Variability of linezolid concentrations after standard dosing in critically ill patients: a prospective observational study. Crit Care 2014;18(4):R148

140 Dong H, Wang X, Dong Y, et al. Clinical pharmacokinetic/ pharmacodynamic profile of linezolid in severely ill intensive care unit patients. Int J Antimicrob Agents 2011;38(4): 296-300

141 Adembri C, Fallani S, Cassetta MI, et al. Linezolid pharmacokinetic/pharmacodynamic profile in critically ill septic patients: intermittent versus continuous infusion. Int J Antimicrob Agents 2008;31(2):122-129 
142 Cattaneo D, Orlando G, Cozzi V, et al. Linezolid plasma concentrations and occurrence of drug-related haematological toxicity in patients with gram-positive infections. Int J Antimicrob Agents 2013;41(6):586-589

143 Livermore DM. Linezolid in vitro: mechanism and antibacterial spectrum. J Antimicrob Chemother 2003;51(Suppl 2):ii9-ii16

144 Sánchez García M, De la Torre MA, Morales G, et al. Clinical outbreak of linezolid-resistant Staphylococcus aureus in an intensive care unit. JAMA 2010;303(22):2260-2264

145 Hentschke M, Saager B, Horstkotte MA, et al. Emergence of linezolid resistance in a methicillin resistant Staphylococcus aureus strain. Infection 2008;36(1):85-87

146 Pai MP, Rodvold KA, Schreckenberger PC, Gonzales RD, Petrolatti JM, Quinn JP. Risk factors associated with the development of infection with linezolid- and vancomycin-resistant Enterococcus faecium. Clin Infect Dis 2002;35(10):1269-1272

147 Wunderink RG, Niederman MS, Kollef MH, et al. Linezolid in methicillin-resistant Staphylococcus aureus nosocomial pneumonia: a randomized, controlled study. Clin Infect Dis 2012;54(5): 621-629

148 Herrmann DJ, Peppard WJ, Ledeboer NA, Theesfeld ML, Weigelt JA, Buechel BJ. Linezolid for the treatment of drug-resistant infections. Expert Rev Anti Infect Ther 2008;6(6):825-848

149 Safdar N, Andes D, Craig WA. In vivo pharmacodynamic activity of daptomycin. Antimicrob Agents Chemother 2004:48(1):63-68

150 Dandekar PK, Tessier PR, Williams P, Zhang C, Nightingale $\mathrm{CH}$, Nicolau DP. Determination of the pharmacodynamic profile of daptomycin against Streptococcus pneumoniae isolates with varying susceptibility to penicillin in a murine thigh infection model. Chemotherapy 2004;50(1):11-16

151 Louie A, Kaw P, Liu W, Jumbe N, Miller MH, Drusano GL. Pharmacodynamics of daptomycin in a murine thigh model of Staphylococcus aureus infection. Antimicrob Agents Chemother 2001;45(3):845-851

152 Dvorchik BH, Brazier D, DeBruin MF, Arbeit RD. Daptomycin pharmacokinetics and safety following administration of escalating doses once daily to healthy subjects. Antimicrob Agents Chemother 2003;47(4):1318-1323

153 Woodworth JR, Nyhart EH Jr, Brier GL, Wolny JD, Black HR. Singledose pharmacokinetics and antibacterial activity of daptomycin, a new lipopeptide antibiotic, in healthy volunteers. Antimicrob Agents Chemother 1992;36(2):318-325

154 Gould IM, David MZ, Esposito S, et al. New insights into meticillinresistant Staphylococcus aureus (MRSA) pathogenesis, treatment and resistance. Int J Antimicrob Agents 2012;39(2):96-104

155 Fowler VG Jr, Boucher HW, Corey GR, et al; S. aureus Endocarditis and Bacteremia Study Group. Daptomycin versus standard therapy for bacteremia and endocarditis caused by Staphylococcus aureus. N Engl J Med 2006;355(7):653-665

156 Liu C, Bayer A, Cosgrove SE, et al. Clinical practice guidelines by the Infectious Diseases Society of America for the treatment of methicillin resistant Staphylococcus aureus infections in adults and children: executive summary. Clin Infect Dis 2011;52(3): 285-292

157 Moise PA, Hershberger E, Amodio-Groton MI, Lamp KC. Safety and clinical outcomes when utilizing high-dose ( $>$ or $=8 \mathrm{mg} / \mathrm{kg}$ ) daptomycin therapy. Ann Pharmacother 2009;43(7):1211-1219

158 Bassetti M, Nicco E, Ginocchio F, Ansaldi F, de Florentiis D, Viscoli C. High-dose daptomycin in documented Staphylococcus aureus infections. Int J Antimicrob Agents 2010;36(5):459-461

159 Figueroa DA, Mangini E, Amodio-Groton M, et al. Safety of high-dose intravenous daptomycin treatment: three-year cumulative experience in a clinical program. Clin Infect Dis 2009;49(2):177-180

160 Falagas ME, Maraki S, Karageorgopoulos DE, Kastoris AC, Mavromanolakis E, Samonis G. Antimicrobial susceptibility of multidrug-resistant (MDR) and extensively drug-resistant (XDR) Enterobacteriaceae isolates to fosfomycin. Int J Antimicrob Agents 2010;35(3):240-243
161 Patel SS, Balfour JA, Bryson HM. Fosfomycin tromethamine. A review of its antibacterial activity, pharmacokinetic properties and therapeutic efficacy as a single-dose oral treatment for acute uncomplicated lower urinary tract infections. Drugs 1997;53(4): 637-656

162 Dinh A, Salomon J, Bru JP, Bernard L. Fosfomycin: efficacy against infections caused by multidrug-resistant bacteria. Scand J Infect Dis 2012;44(3):182-189

163 Thauvin C, Lemeland JF, Humbert G, Fillastre JP. Efficacy of pefloxacin-fosfomycin in experimental endocarditis caused by methicillin-resistant Staphylococcus aureus. Antimicrob Agents Chemother 1988;32(6):919-921

164 Portier H, Kazmierczak A, Lucht F, Tremeaux JC, Chavanet P, Duez JM. Cefotaxime in combination with other antibiotics for the treatment of severe methicillin-resistant staphylococcal infections. Infection 1985;13(Suppl 1):S123-S128

165 Komatsuzawa H, Suzuki J, Sugai M, Miyake Y, Suginaka H. Effect of combination of oxacillin and non-beta-lactam antibiotics on methicillin-resistant Staphylococcus aureus. J Antimicrob Chemother 1994;33(6):1155-1163

166 Sahuquillo Arce JM, Colombo Gainza E, Gil Brusola A, Ortiz Estévez R, Cantón E, Gobernado M. In vitro activity of linezolid in combination with doxycycline, fosfomycin, levofloxacin, rifampicin and vancomycin against methicillin-susceptible Staphylococcus aureus. Rev Esp Quimioter 2006;19(3):252-257

167 Ferrara A, Dos Santos C, Cimbro M, Gialdroni Grassi G. Effect of different combinations of sparfloxacin, oxacillin, and fosfomycin against methicillin-resistant staphylococci. Eur J Clin Microbiol Infect Dis 1997;16(7):535-537

168 Okazaki M, Suzuki K, Asano N, et al. Effectiveness of fosfomycin combined with other antimicrobial agents against multidrugresistant Pseudomonas aeruginosa isolates using the efficacy time index assay. J Infect Chemother 2002;8(1):37-42

169 Hayami H, Goto T, Kawahara M, Ohi Y. Activities of beta-lactams, fluoroquinolones, amikacin and fosfomycin alone and in combination against Pseudomonas aeruginosa isolated from complicated urinary tract infections. J Infect Chemother 1999;5(3): 130-138

170 Reguera JA, Baquero F, Berenguer J, Martinez-Ferrer M, Martinez JL. Beta-lactam-fosfomycin antagonism involving modification of penicillin-binding protein 3 in Pseudomonas aeruginosa. Antimicrob Agents Chemother 1990;34(11):2093-2096

171 Michalopoulos A, Virtzili S, Rafailidis P, Chalevelakis G, Damala M, Falagas ME. Intravenous fosfomycin for the treatment of nosocomial infections caused by carbapenem-resistant Klebsiella pneumoniae in critically ill patients: a prospective evaluation. Clin Microbiol Infect 2010;16(2):184-186

172 Li J, Turnidge J, Milne R, Nation RL, Coulthard K. In vitro pharmacodynamic properties of colistin and colistin methanesulfonate against Pseudomonas aeruginosa isolates from patients with cystic fibrosis. Antimicrob Agents Chemother 2001;45(3): 781-785

173 Dudhani RV, Turnidge JD, Coulthard K, et al. Elucidation of the pharmacokinetic/pharmacodynamic determinant of colistin activity against Pseudomonas aeruginosa in murine thigh and lung infection models. Antimicrob Agents Chemother 2010;54(3): 1117-1124

174 Dudhani RV, Turnidge JD, Nation RL, Li J. fAUC/MIC is the most predictive pharmacokinetic/pharmacodynamic index of colistin against Acinetobacter baumannii in murine thigh and lung infection models. J Antimicrob Chemother 2010;65(9):1984-1990

175 Lim LM, Ly N, Anderson D, et al. Resurgence of colistin: a review of resistance, toxicity, pharmacodynamics, and dosing. Pharmacotherapy 2010;30(12):1279-1291

176 Yau W, Owen RJ, Poudyal A, et al. Colistin hetero-resistance in multidrug-resistant Acinetobacter baumannii clinical isolates from the Western Pacific region in the SENTRY antimicrobial surveillance programme. J Infect 2009;58(2):138-144 
177 Hawley JS, Murray CK, Jorgensen JH. Colistin heteroresistance in acinetobacter and its association with previous colistin therapy. Antimicrob Agents Chemother 2008;52(1):351-352

178 Poudyal A, Howden BP, Bell JM, et al. In vitro pharmacodynamics of colistin against multidrug-resistant Klebsiella pneumoniae. J Antimicrob Chemother 2008;62(6):1311-1318

179 Bergen PJ, Forrest A, Bulitta JB, et al. Clinically relevant plasma concentrations of colistin in combination with imipenem enhance pharmacodynamic activity against multidrug-resistant Pseudomonas aeruginosa at multiple inocula. Antimicrob Agents Chemother 2011;55(11):5134-5142

180 Bergen PJ, Li J, Nation RL, Turnidge JD, Coulthard K, Milne RW. Comparison of once-, twice- and thrice-daily dosing of colistin on antibacterial effect and emergence of resistance: studies with Pseudomonas aeruginosa in an in vitro pharmacodynamic model. J Antimicrob Chemother 2008;61(3):636-642

181 Tan CH, Li J, Nation RL. Activity of colistin against heteroresistant Acinetobacter baumannii and emergence of resistance in an in vitro pharmacokinetic/pharmacodynamic model. Antimicrob Agents Chemother 2007;51(9):3413-3415

182 Garonzik SM, Li J, Thamlikitkul V, et al. Population pharmacokinetics of colistin methanesulfonate and formed colistin in critically ill patients from a multicenter study provide dosing suggestions for various categories of patients. Antimicrob Agents Chemother 2011;55(7):3284-3294

183 Marchand S, Frat JP, Petitpas F, et al. Removal of colistin during intermittent haemodialysis in two critically ill patients. J Antimicrob Chemother 2010;65(8):1836-1837

184 Plachouras D, Karvanen M, Friberg LE, et al. Population pharmacokinetic analysis of colistin methanesulfonate and colistin after intravenous administration in critically ill patients with infections caused by gram-negative bacteria. Antimicrob Agents Chemother 2009;53(8):3430-3436

185 Dalfino L, Puntillo F, Mosca A, et al. High-dose, extended-interval colistin administration in critically ill patients: is this the right dosing strategy? A preliminary study. Clin Infect Dis 2012;54(12): 1720-1726

186 Karvanen M, Plachouras D, Friberg LE, et al. Colistin methanesulfonate and colistin pharmacokinetics in critically ill patients receiving continuous venovenous hemodiafiltration. Antimicrob Agents Chemother 2013;57(1):668-671

187 Markou N, Fousteri M, Markantonis SL, et al. Colistin pharmacokinetics in intensive care unit patients on continuous venovenous haemodiafiltration: an observational study. J Antimicrob Chemother 2012;67(10):2459-2462

188 Matthaiou DK, Michalopoulos A, Rafailidis PI, et al. Risk factors associated with the isolation of colistin-resistant gram-negative bacteria: a matched case-control study. Crit Care Med 2008; 36(3):807-811

189 Mentzelopoulos SD, Pratikaki M, Platsouka E, et al. Prolonged use of carbapenems and colistin predisposes to ventilator-associated pneumonia by pandrug-resistant Pseudomonas aeruginosa. Intensive Care Med 2007;33(9):1524-1532

190 Martínez JA, Cobos-Trigueros N, Soriano A, et al. Influence of empiric therapy with a beta-lactam alone or combined with an aminoglycoside on prognosis of bacteremia due to gram-negative microorganisms. Antimicrob Agents Chemother 2010;54(9): 3590-3596

191 Kumar A, Zarychanski R, Light B, et al; Cooperative Antimicrobial Therapy of Septic Shock (CATSS) Database Research Group. Early combination antibiotic therapy yields improved survival compared with monotherapy in septic shock: a propensity-matched analysis. Crit Care Med 2010;38(9):1773-1785

192 Kumar A, Safdar N, Kethireddy S, Chateau D. A survival benefit of combination antibiotic therapy for serious infections associated with sepsis and septic shock is contingent only on the risk of death: a meta-analytic/meta-regression study. Crit Care Med 2010;38(8):1651-1664
193 Chamot E, Boffi El Amari E, Rohner P, Van Delden C. Effectiveness of combination antimicrobial therapy for Pseudomonas aeruginosa bacteremia. Antimicrob Agents Chemother 2003;47(9): 2756-2764

194 Cosgrove SE, Vigliani GA, Fowler VG Jr, et al. Initial low-dose gentamicin for Staphylococcus aureus bacteremia and endocarditis is nephrotoxic. Clin Infect Dis 2009;48(6):713-721

195 Riedel DJ, Weekes E, Forrest GN. Addition of rifampin to standard therapy for treatment of native valve infective endocarditis caused by Staphylococcus aureus. Antimicrob Agents Chemother 2008;52(7):2463-2467

196 Falagas ME, Matthaiou DK, Bliziotis IA. The role of aminoglycosides in combination with a beta-lactam for the treatment of bacterial endocarditis: a meta-analysis of comparative trials. J Antimicrob Chemother 2006;57(4):639-647

197 Vardakas KZ, Tansarli GS, Bliziotis IA, Falagas ME. $\beta$-Lactam plus aminoglycoside or fluoroquinolone combination versus $\beta$-lactam monotherapy for Pseudomonas aeruginosa infections: a metaanalysis. Int J Antimicrob Agents 2013;41(4):301-310

198 Peña C, Suarez C, Ocampo-Sosa A, et al; Spanish Network for Research in Infectious Diseases (REIPI). Effect of adequate singledrug vs combination antimicrobial therapy on mortality in Pseudomonas aeruginosa bloodstream infections: a post hoc analysis of a prospective cohort. Clin Infect Dis 2013;57(2): 208-216

199 Marcus R, Paul M, Elphick H, Leibovici L. Clinical implications of $\beta$ lactam-aminoglycoside synergism: systematic review of randomised trials. Int J Antimicrob Agents 2011;37(6):491-503

200 Louie A, Grasso C, Bahniuk N, et al. The combination of meropenem and levofloxacin is synergistic with respect to both Pseudomonas aeruginosa kill rate and resistance suppression. Antimicrob Agents Chemother 2010;54(6):2646-2654

201 den Hollander JG, Horrevorts AM, van Goor ML, Verbrugh HA, Mouton JW. Synergism between tobramycin and ceftazidime against a resistant Pseudomonas aeruginosa strain, tested in an in vitro pharmacokinetic model. Antimicrob Agents Chemother 1997;41(1):95-100

202 Mouton JW, van Ogtrop ML, Andes D, Craig WA. Use of pharmacodynamic indices to predict efficacy of combination therapy in vivo. Antimicrob Agents Chemother 1999;43(10): 2473-2478

203 Zavascki AP, Bulitta JB, Landersdorfer CB. Combination therapy for carbapenem-resistant Gram-negative bacteria. Expert Rev Anti Infect Ther 2013;11(12):1333-1353

204 Epstein BJ, Gums JG, Drlica K. The changing face of antibiotic prescribing: the mutant selection window. Ann Pharmacother 2004;38(10):1675-1682

205 Zhanel GG, Mayer M, Laing N, Adam HJ. Mutant prevention concentrations of levofloxacin alone and in combination with azithromycin, ceftazidime, colistin (Polymyxin E), meropenem, piperacillin-tazobactam, and tobramycin against Pseudomonas aeruginosa. Antimicrob Agents Chemother 2006;50(6): 2228-2230

206 Lister PD, Wolter DJ. Levofloxacin-imipenem combination prevents the emergence of resistance among clinical isolates of Pseudomonas aeruginosa. Clin Infect Dis 2005;40(2, Suppl 2): S105-S114

207 Firsov AA, Vostrov SN, Lubenko IY, Portnoy YA, Zinner SH. Prevention of the selection of resistant Staphylococcus aureus by moxifloxacin plus doxycycline in an in vitro dynamic model: an additive effect of the combination. Int J Antimicrob Agents 2004;23(5):451-456

208 Drusano GL, Liu W, Fregeau C, Kulawy R, Louie A. Differing effects of combination chemotherapy with meropenem and tobramycin on cell kill and suppression of resistance of wild-type Pseudomonas aeruginosa PAO1 and its isogenic MexAB efflux pump-overexpressed mutant. Antimicrob Agents Chemother 2009;53(6): 2266-2273 
209 Mendes RE, Fritsche TR, Sader HS, Jones RN. Increased antimicrobial susceptibility profiles among polymyxin-resistant Acinetobacter baumannii clinical isolates. Clin Infect Dis 2008;46(8): 1324-1326

210 Mantzarlis K, Makris D, Manoulakas E, Karvouniaris M, Zakynthinos E. Risk factors for the first episode of Klebsiella pneumoniae resistant to carbapenems infection in critically ill patients: a prospective study. Biomed Res Int 2013;2013:850547

211 Micek ST, Ward S, Fraser VJ, Kollef MH. A randomized controlled trial of an antibiotic discontinuation policy for clinically suspected ventilator-associated pneumonia. Chest 2004;125(5):1791-1799

212 Chastre J, Wolff M, Fagon JY, et al; PneumA Trial Group. Comparison of 8 vs 15 days of antibiotic therapy for ventilator-associated pneumonia in adults: a randomized trial. JAMA 2003;290(19): 2588-2598

213 Singh N, Rogers P, Atwood CW, Wagener MM, Yu VL. Shortcourse empiric antibiotic therapy for patients with pulmonary infiltrates in the intensive care unit. A proposed solution for indiscriminate antibiotic prescription. Am J Respir Crit Care Med 2000;162(2, Pt 1):505-511
214 Taccone FS, Laterre PF, Spapen H, et al. Revisiting the loading dose of amikacin for patients with severe sepsis and septic shock. Crit Care 2010;14(2):R53

215 Rea RS, Capitano B, Bies R, Bigos KL, Smith R, Lee H. Suboptimal aminoglycoside dosing in critically ill patients. Ther Drug Monit 2008;30(6):674-681

216 Gonçalves-Pereira J, Póvoa P. Antibiotics in critically ill patients: a systematic review of the pharmacokinetics of $\beta$-lactams. Crit Care 2011;15(5):R206

217 Buerger C, Plock N, Dehghanyar P, Joukhadar C, Kloft C. Pharmacokinetics of unbound linezolid in plasma and tissue interstitium of critically ill patients after multiple dosing using microdialysis. Antimicrob Agents Chemother 2006;50(7):2455-2463

218 Tsuji BT, Brown T, Parasrampuria R, et al. Front-loaded linezolid regimens result in increased killing and suppression of the accessory gene regulator system of Staphylococcus aureus. Antimicrob Agents Chemother 2012;56(7):3712-3719

219 Mohd Hafiz AA, Staatz CE, Kirkpatrick CM, Lipman J, Roberts JA. Continuous infusion vs. bolus dosing: implications for betalactam antibiotics. Minerva Anestesiol 2012;78(1):94-104 